\title{
Protonated Adenine: Tautomers, Solvated Clusters, and Dissociation Mechanisms
}

\author{
František Tureček and Xiaohong Chen \\ Department of Chemistry, University of Washington, Seattle, Washington, USA
}

$\mathrm{Ab}$ initio and density functional theory calculations at the B3-MP2 and CCSD(T)/6-311 + $\mathrm{G}(3 \mathrm{df}, 2 \mathrm{p})$ levels of theory are reported that address the protonation of adenine in the gas phase, water clusters, and bulk aqueous solution. The calculations point to N-1-protonated adenine $\left(\mathbf{1}^{+}\right)$as the thermodynamically most stable cationic tautomer in the gas phase, water clusters, and bulk solution. This strongly indicates that electrospray ionization of adenine solutions produces tautomer $\mathbf{1}^{+}$with a specificity calculated as $97-90 \%$ in the $298-473 \mathrm{~K}$ temperature range. The mechanisms for elimination of hydrogen atoms and ammonia from $\mathbf{1}^{+}$ have also been studied computationally. Ion $\mathbf{1}^{+}$is calculated to undergo fast migrations of protons among positions $\mathrm{N}-1, \mathrm{C}-2, \mathrm{~N}-3, \mathrm{~N}-10, \mathrm{~N}-7$, and $\mathrm{C}-8$ that result in an exchange of five hydrogens before loss of a hydrogen atom forming adenine cation radical at $415 \mathrm{~kJ} \mathrm{~mol}^{-1}$ dissociation threshold energy. The elimination of ammonia is found to be substantially endothermic requiring 376-380 $\mathrm{kJ} \mathrm{mol}^{-1}$ at the dissociation threshold and depending on the dissociation pathway. The overall dissociation is slowed by the involvement of ion-molecule complexes along the dissociation pathways. The competing isomerization of $\mathbf{1}^{+}$proceeds by a sequence of ring opening, internal rotations, imine flipping, ring closures, and proton migrations to effectively exchange the $\mathrm{N}-1$ and $\mathrm{N}-10$ atoms in $\mathbf{1}^{+}$, so that either can be eliminated as ammonia. This mechanism explains the previous $\mathrm{N}-1 / \mathrm{N}-10$ exchange upon collision-induced dissociation of protonated adenine. (J Am Soc Mass Spectrom 2005, 16, 1713-1726) ( 2005 American Society for Mass Spectrometry

$\mathrm{P}_{\mathrm{s}}$ rotonation of adenine, adenosine, and adeninecontaining nucleotides has been of interest to gas phase and solution chemists alike. In aqueous solution, adenine and adenosine prefer to be protonated at $\mathrm{N}-1$ [1], as unequivocally established by ${ }^{1} \mathrm{H}-\mathrm{NMR}$ studies [2].

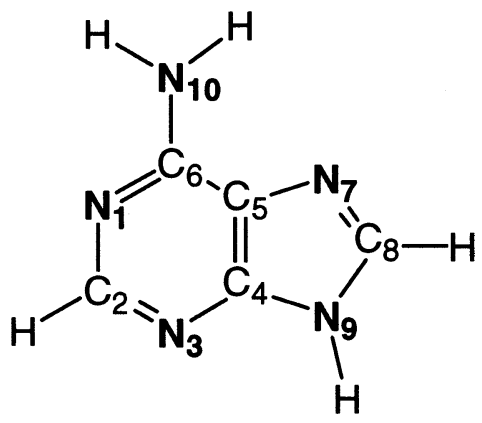

In the gas phase, adenine is protonated at one of the basic nitrogen atoms, and the composition of the tautomer mixture depends on the reaction conditions [3].

Published online August 15, 2005

Address reprint requests to Dr. F. Tureček, Department of Chemistry, University of Washington, Bagley Hall, Box 351700, Seattle, WA 98195-1700,

USA. E-mail: turecek@chem.washington.edu
Of particular interest to mass spectrometrists are the dissociations of protonated adenine, as observed following collisional activation. Collisionally activated dissociation (CAD) mass spectra of ions corresponding to protonated adenine have been studied for ions obtained by dissociation of adenosine upon atmospheric pressure chemical ionization [4], and by fast-atom bombardment ionization of adenine in glycerol matrix [5]. The CAD spectra of adenine $(\mathrm{M}+\mathrm{H})^{+}$ions obtained at 30-50 eV collision energies in the laboratory reference frame $\left(\mathrm{E}_{\mathrm{LAB}}\right)$ showed mainly eliminations of ammonia, hydrogen cyanide, $\left(\mathrm{NH}_{3}+\mathrm{HCN}\right)$ and fragments due to ring cleavages. The loss of ammonia dominates the dissociations at $\mathrm{E}_{\mathrm{LAB}}=30 \mathrm{eV}$. In contrast, CAD spectra obtained at $\mathrm{keV}$ collision energies $\left(\mathrm{E}_{\mathrm{LAB}}=8-10 \mathrm{keV}\right)$ showed a major loss of a hydrogen atom in addition to the dissociations found in the low-energy CAD spectra [3]. The difference between the $30-\mathrm{eV}$ and $8-\mathrm{keV}$ CAD spectra is very dramatic indeed, as the former shows no fragments at $m / z 135$ due to loss of $\mathrm{H}$ [5], whereas in the latter $\mathrm{m} / \mathrm{z} 135$ is the most abundant fragment ion [3].

Isotope labeling revealed that the elimination of ammonia involved mainly (97\%) the nitrogen atoms from $\mathrm{N}-1$ and the amino group (N-10), and the ammonia molecule contained these nitrogen atoms with nearly equal probability (44:56). A complementary $\mathrm{NH}_{4}^{+}$fragment in the $30-\mathrm{eV} \mathrm{CAD} \mathrm{spectrum} \mathrm{was} \mathrm{found}$ to originate mainly $(90 \%)$ from $\mathrm{N}-1$ with minor contri- 
butions from N-3 (2\%) and N-10 (8\%) [5]. Interestingly, CAD spectra obtained at $\mathrm{E}_{\mathrm{LAB}}=30 \mathrm{eV}$ under nearsingle collision conditions showed ca. 3.5:1 ratio for loss of ammonia involving the $\mathrm{N}-1$ and $\mathrm{N}-10$ positions. Loss of ammonia from protonated adenine upon CAD at $10-\mathrm{keV}$ involves $11-13 \%$ hydrogen atoms from each $\mathrm{C}-2, \mathrm{C}-8$, and $\mathrm{N}-9$, the main source of $\mathrm{H}$ atoms being the $\mathrm{N}-1$ and $\mathrm{N}-10$ protons [3]. In contrast, the loss of an $\mathrm{H}$ atom is nearly statistical and involves $\mathrm{H}$ atoms from all positions in protonated adenine [3].

Experimental data also indicate that CAD of protonated adenine is fairly inefficient. At $10 \mathrm{keV}$ and $50 \%$ ion beam transmittance $(69 \%$ single and 30\% double collisions), only $1 \%$ of protonated adenine dissociated by loss of ammonia [3]. At $50 \mathrm{eV}$ and multiple collision conditions, the efficiency of CAD loss of ammonia was about $10 \%$ [4]. This suggests that loss of ammonia requires a substantial energy at the dissociation threshold or in the transition-state of the rate-determining step.

The loss of ammonia involving $\mathrm{N}-1$ and $\mathrm{N}-10$ raises the question of the dissociation mechanism that has not been satisfactorily answered by the previous work. Based on ${ }^{15} \mathrm{~N}$ labeling, Nelson and McCloskey postulated that protonation at N-1 in adenine weakens the $\mathrm{N}-1-\mathrm{C}-2$ bond and causes ring opening that results in equilibration of the N-1 and N-10 positions [5]. However, the energetics of such dissociation has not been addressed. Unexplained, also, remains the peculiar increased selectivity in the loss of $\mathrm{N}$-1-containing ammonia under single-collision CAD conditions that obviously cannot result from equilibration of the N-1 and N-10 nitrogens.

The goal of the present work is to provide structures and energies for reactants, intermediates, transition states, and products relevant to the dissociation pathways leading to loss of ammonia from protonated adenine. To this end, we have conducted extensive ab initio and density functional theory calculations at high levels of theory, and attempted to quantify the branching ratios in the product formation through unimolecular rate constants obtained by Rice-Ramsperger-KasselMarcus theory. We also address by computations the question of adenine protonation selectivity in the gas phase and aqueous solution.

\section{Calculations}

Standard ab initio and density functional theory calculations were performed using the Gaussian 03 suite of programs [6]. Geometries were optimized with Becke's hybrid functional (B3LYP) [7] using the 6-31 + G(d,p) basis set. The optimized structures for most relevant species are shown in Figures 1, 2, and 3. Complete geometries in the Cartesian coordinate format are available as Supplementary Material. The same level of theory was used for frequency analysis to characterize local energy minima (all real frequencies) and transition states as first-order saddle points (one imaginary fre- quency). Improved energies were obtained by singlepoint calculations using B3LYP and Moller-Plesset theory [8] truncated at second-order ( $\mathrm{MP} 2$, frozen core) and the larger triple- $\xi$ split valence $6-311++\mathrm{G}(3 \mathrm{df}, 2 \mathrm{p})$ basis set furnished with multiple shells of polarization functions at $\mathrm{C}, \mathrm{N}$, and $\mathrm{H}$ and one shell of $\mathrm{s}$ and $\mathrm{p}$ diffuse functions at $C$ and N. A further increase of the basis set to $6-311+\mathrm{G}(3 \mathrm{df}, 2 \mathrm{p})$ had a negligible effect on both the total and relative energies that changed by $\Delta E=-0.016$ millihartree and $0.22 \mathrm{~kJ} \mathrm{~mol}^{-1}$, respectively. The B3LYP and MP2 single point energies were averaged according to the previously reported B3-MP2 scheme [9] that has been shown to achieve improved accuracy at the level of highly correlated composite ab initio methods by canceling small errors inherent to the B3LYP and MP2 approximations [10,11]. Another set of energies was obtained for selected species from single point calculations with coupled cluster theory [12] employing single, double, and disconnected triple excitations of valence electrons [13], $\operatorname{CCSD}(\mathrm{T})$, and the $6-31 \mathrm{G}(\mathrm{d}, \mathrm{p})$ basis set. The energies were extrapolated to $\operatorname{CCSD}(\mathrm{T}) / 6-311+$ $\mathrm{G}(3 \mathrm{df}, 2 \mathrm{p})$ using the standard linear formula, eq 1 .

$$
\begin{aligned}
& E[\operatorname{CCSD}(\mathrm{T}) / 6-311+\mathrm{G}(3 \mathrm{df}, 2 \mathrm{p})] \\
& \approx E[\operatorname{CCSD}(\mathrm{T}) / 6-31 \mathrm{G}(\mathrm{d}, \mathrm{p})]+E[\mathrm{MP} 2 / 6-311 \\
& \quad+\mathrm{G}(3 \mathrm{df}, 2 \mathrm{p})]-E[\mathrm{MP} 2 / 6-31 \mathrm{G}(\mathrm{d}, \mathrm{p})]
\end{aligned}
$$

The B3-MP2 and CCSD(T) energies were used to calculate relative energies that were corrected for zero-point vibrational contributions. The reported relative energies thus correspond to $0 \mathrm{~K}$ unless stated otherwise. Enthalpy corrections and entropies were calculated from B3LYP/6-31 + G(d,p) harmonic frequencies and moments of inertia within the rigid rotor-harmonic oscillator approximation.

Solvation free energies were calculated using the refined polarizable continuum model (PCM) of Tomasi et al. [14a] included in Gaussian 03. As noted in the program, this PCM model is different from that included in Gaussian 98 [15], and the free energies from these two models should not be mixed.

RRKM calculations were performed using Hase and Zhu's program [16] that was recompiled and run under Windows XP [17]. Direct count of quantum states was used in $2 \mathrm{~kJ} \mathrm{~mol}^{-1}$ steps from the transition-state energy up to $600 \mathrm{~kJ} \mathrm{~mol}^{-1}$ above it. Rotational states were treated adiabatically or as active modes in separate runs. These two treatments gave rate constants that were within $0.5 \%$ at each energy point and were considered equivalent. The calculated microscopic rate constants, $k(E, J, K)$, were Boltzmann averaged over the rotational states at $473 \mathrm{~K}$, corresponding to the ion source temperature that defines the precursor ion rotational temperature, to give microcanonical rate constants $k(E)$. Variational transition-state theory [18] was used for calculations of dissociations that did not have well defined saddle points on the potential energy surface. Harmonic frequencies, moments of inertia, and 


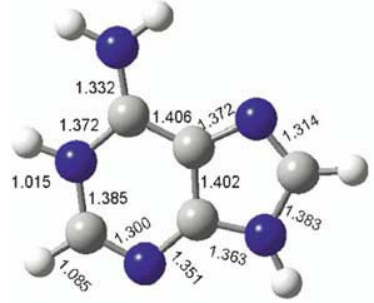

$1^{+}$

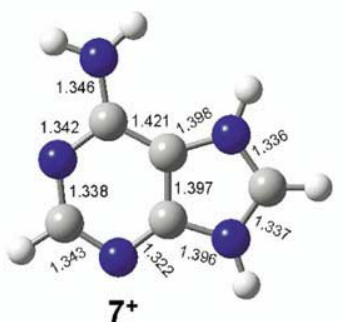

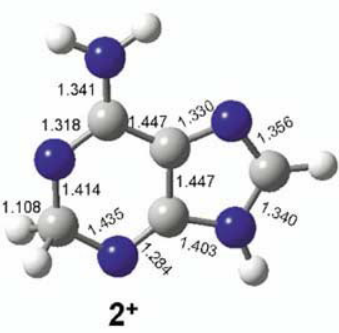

$2^{+}$

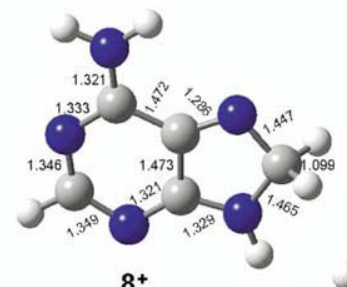

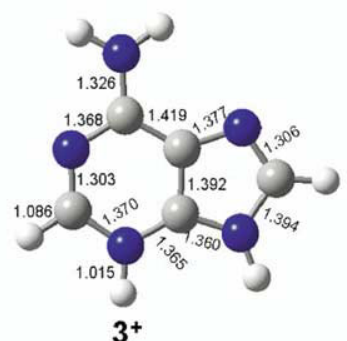

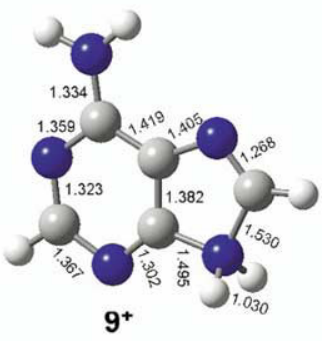

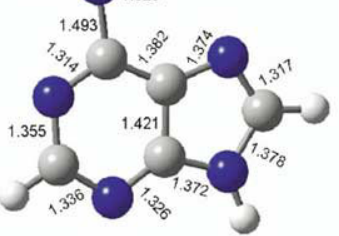

$10^{+}$

Figure 1. B3LYP/6-31 $+\mathrm{G}(\mathrm{d}, \mathrm{p})$ optimized structures of protonated adenine tautomers $\mathbf{1}^{+}-3^{+}$and $\mathbf{7}^{+}-10^{+}$.

single point B3-MP2 energies were obtained at several points along the reaction coordinate up to the rotational barrier limit and used to calculate $k(E)$. The point with the smallest $k(E)$ was assigned the transition state for the dissociation (canonical variational criterion) [19].

\section{Results and Discussion}

Adenine Protonation in the Gas Phase

In the previous experimental work, adenine was protonated in the gas phase under low-pressure CI condi-

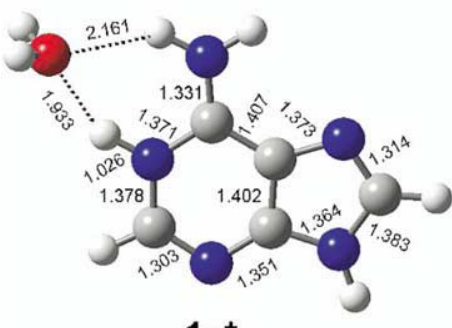

$1 \mathrm{a}^{+}$

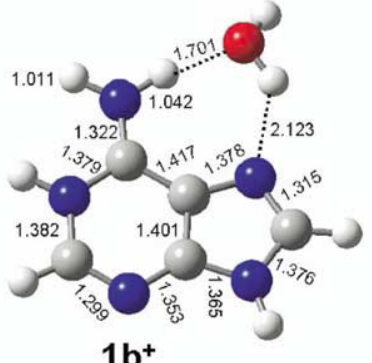

$1 b^{+}$
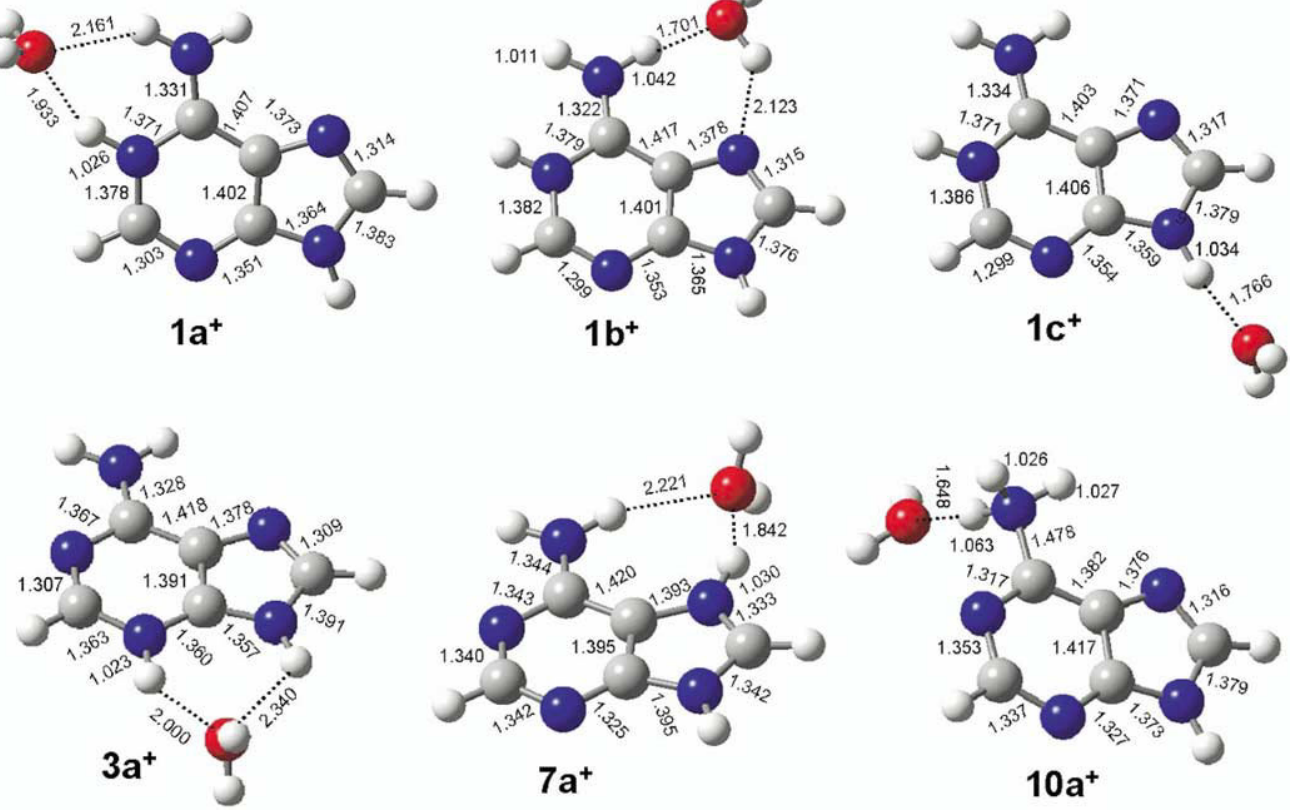

Figure 2. B3LYP/6-31 $+\mathrm{G}\left(\mathrm{d}\right.$,p) optimized structures of protonated [adenine $+\mathrm{H}_{2} \mathrm{O}$ ] clusters. 
tions using different gas-phase acids [3], in the FAB plume from a glycerol matrix [5], and in aqueousmethanol solution droplets by electrospray ionization [20]. Since the question of protonation sites in adenine is relevant to the present study, we address it in some detail before the discussion of dissociation mechanisms of protonated adenine.

The topical proton affinities (PA) of adenine in the gas phase have been addressed by several calculations at various levels of theory [21]. According to the highest levels of theory used, which were $\operatorname{CCSD}(\mathrm{T}) / 6-311++$ $\mathrm{G}(3 \mathrm{df}, 2 \mathrm{p})$ and B3-MP2/6-311 + G(3df,2p) [3], N-1 is the most basic position in adenine, $(\mathrm{PA}(\mathrm{N}-1)=939 \mathrm{~kJ}$ $\left.\mathrm{mo1}^{-1}\right)$, followed by N-3 $\left(\mathrm{PA}=932 \mathrm{~kJ} \mathrm{mo1}{ }^{-1}\right), \mathrm{N}-7(\mathrm{PA}=$ $\left.904 \mathrm{~kJ} \mathrm{mo1}^{-1}\right)$, and $\mathrm{N}-10\left(\mathrm{PA}=846-850 \mathrm{~kJ} \mathrm{mo1}^{-1}\right)$. The carbon atoms C-2, C-4, C-5, C- $6, \mathrm{C}-8$, and the N-9 position have very low basicities $\left(\mathrm{PA}<800 \mathrm{~kJ} \mathrm{~mol}^{-1}\right.$ ) [3] and do not have to be considered in the context of protonation. The gas-phase equilibria for protonation at the two most basic N-1 (ion $\mathbf{1}^{+}$, Figure 1 ) and N-3 positions (ion $3^{+}$) give $\Delta G_{\mathrm{T}}^{\mathrm{o}}\left(\mathbf{1}^{+} \rightarrow 3^{+}\right)=6.8$ and $6.7 \mathrm{~kJ}$ mo1 ${ }^{-1}$ at 298 and $473 \mathrm{~K}$, respectively, favoring $\mathbf{1}^{+}$. Thus, under equilibrium conditions, protonation at $\mathrm{N}-1$ is predicted to be favored over $\mathrm{N}-3$ at $94 / 6$ and $85 / 15 \%$ at $298 \mathrm{~K}$ and $473 \mathrm{~K}$, respectively. The third most basic position $\left(\mathrm{N}-7\right.$, ion $\left.7^{+}\right)$is calculated to be disfavored against $\mathrm{N}-1$ by $\Delta \mathrm{G}_{\mathrm{T}}^{\mathrm{o}}\left(\mathbf{1}^{+} \rightarrow 7^{+}\right)=33$ and $32 \mathrm{~kJ} \mathrm{mo}^{-1}$ at 298 and $473 \mathrm{~K}$, respectively, and would amount to $<0.3 \%$ of $7^{+}$at equilibrium. The optimized structures of protonated tautomers $1^{+}, 2^{+}, 3^{+}, 7^{+}, 8^{+}, 9^{+}$, and $10^{+}$are given in Figure 1.

It should be noted that protonation by $\mathrm{CI}$ or $\mathrm{FAB}$ typically does not proceed under equilibrium conditions. CI on beam instruments is conducted at 0.1-1.0 torr of the reagent gas and the ions are extracted within a few microseconds from the ion source, which dictates that the proton transfer kinetics be fast to achieve good yields of protonated analyte ions. Hence, gas-phase protonation is typically conducted such as to occur at the collisional rate, which requires that the proton transfer be substantially exoergic [22], e.g., for protonation with $\mathrm{NH}_{4}^{+}$according to eq 2:

$$
\begin{gathered}
\text { Adenine }+\mathrm{NH}_{4}^{+} \rightarrow \mathbf{1}^{+}+\mathrm{NH}_{3} \\
\Delta H_{\mathrm{rxn}, 298}=-86 \mathrm{~kJ} \mathrm{~mol}^{-1}
\end{gathered}
$$

Under these conditions, reversible and endoergic proton transfer from $\mathbf{1}^{+}$to ammonia is highly inefficient given the $\mathrm{NH}_{3}$ partial pressure in the ion source, the ion residence time there, and the limited number of collisions that the ions undergo in the high-pressure $\mathrm{CI}$ ion source $(<100)$ [3]. Hence, CI-protonation of adenine at $\mathrm{N}-1, \mathrm{~N}-3$, and N-7 can be expected to be dominated by kinetic effects, not thermochemistry, because the necessary condition of proton transfer exoergicity is fulfilled for all these three positions.

Similar conditions apply to protonation by FAB, which occurs at reaction times on the order of micro- seconds, and where the reactant acids are protonated glycerol, its proton-bound oligomers, and ionized fragments [23]. These are all substantially less basic than adenine, making the protonation highly exothermic. For example, the PA of glycerol $\left(875 \mathrm{~kJ} \mathrm{~mol}^{-1}\right)$ and its fragments, e.g., glycolaldehyde $\left(777-780 \mathrm{~kJ} \mathrm{~mol}^{-1}\right)$ make the cations in the glycerol FAB matrix sufficiently acidic to irreversibly transfer a proton on adenine under kinetically controlled conditions. Although the previous investigators presumed that adenine was protonated at N-1 in their FAB/MS experiments [5], their assumption was based on ion thermochemistry, not kinetics. It is therefore possible, even likely, that $\mathrm{CI}$ and FAB protonation of adenine under nonequilibrium conditions produced mixtures of thermodynamically allowed tautomers.

\section{Protonated Adenine Tautomers in Water}

Protonation of adenine under equilibrium conditions in water occurs preferentially at $\mathrm{N}-1$ with $\mathrm{pK}_{\mathrm{B}}=4.0[1,2]$. Calculations of the solvation energies of protonated adenine tautomers, using the polarizable continuum model (PCM), explain well this selectivity. The freeenergy data in Table 1 indicate that position N-1 in adenine in water is $48-130$ times more basic than $\mathrm{N}-3$ (depending on the PCM model used, [14, 15], and 250-319 times more basic than N-7. The N-10 amino group has a negligible basicity in water. The relative basicities in water are composed from the relative free energies in the gas phase $\left(\Delta G_{\mathrm{g}, 298}^{\mathrm{o}}\right)$ and the solvation energies $\left(\Delta G_{\text {solv }}\right)$ in a polar dielectric with the dielectric constant of water. The latter were calculated using two PCM models that gave slightly different solvation energies. Table 1 data show that the relative topical basicities in adenine are determined mainly by the $\Delta G_{\mathrm{g}, 298}^{\mathrm{o}}$. Amongst the isomers, cation $7^{+}$receives the highest stabilization by solvation with water, but this effect is insufficient to reverse the relative stabilities for the gas-phase tautomers. Cations $\mathbf{1}^{+}$and $3^{+}$have similar solvation free energies, so that the $\Delta G_{\mathrm{g}, 298}^{\mathrm{o}}$ difference in the gas phase is transferred to and even slightly increased in aqueous solution. Thus, if adenine is protonated in an aqueous solution, such as in acidic droplets produced by electrospray, equilibrium proton transfer should greatly favor formation of $\mathbf{1}^{+}$against its tautomers. Note that proton transfer between the solvent and the solute is extremely rapid in water [24], and so tautomer equilibrium can be expected to be complete on the $\sim 1$ ms lifetime of the droplet [25], as corroborated by previous studies of $\mathrm{pH}$ effects and equilibria in electrospray droplets [26].

\section{Protonated Adenine Tautomers in Water Clusters}

Adenine cations formed by electrospray [20] undergo phase transition from solution to the gas phase that may involve intermediate gaseous clusters of the cation with one or more molecules of solvent. To address this issue, 
Table 1. Relative enthalpies and free energies of selected tautomers of protonated adenine

\begin{tabular}{crccc}
\hline & \multicolumn{4}{c}{ Relative energy $^{\mathrm{a}}$} \\
\cline { 2 - 5 } lon & $\Delta H_{\mathrm{g}, 0}^{\mathrm{o}}{ }^{\mathrm{b}}$ & $\Delta G_{\mathrm{g}, 298}^{\mathrm{o}}{ }^{\mathrm{c}}$ & $\Delta G_{\mathrm{solv}}{ }^{\mathrm{d}}$ & $\Delta G_{\mathrm{aq}, 298}^{\mathrm{o}}$ \\
\hline \hline $\mathbf{1}^{+}$ & 0 & 0.0 & $-296(-275)^{\mathrm{f}}$ & 0 \\
$\mathbf{2}^{+}$ & 219 & - & - & - \\
$\mathbf{3}^{+}$ & 7 & 6.8 & $-295(-271)$ & $8.3(11)^{\mathrm{f}}$ \\
$\mathbf{7}^{+}$ & 34 & 33 & $-315(-294)$ & $14.0(14.6)$ \\
$\mathbf{8}^{+}$ & 157 & - & - & - \\
$\mathbf{9}^{+}$ & 193 & - & - & - \\
$\mathbf{1 0}^{+}$ & 91 & 86 & $-304(-291)$ & $79(70)$ \\
\hline
\end{tabular}

${ }^{\text {aln }}$ units of $\mathrm{kJ} \mathrm{mol}^{-1}$.

belative enthalpies in the gas phase from B3-MP2/6-311 + G(3df,2p) single point energies and B3LYP/6-31 + G(d,p) ZPVE corrections.

'Relative free energies in the gas phase from B3-MP2/6-311 + G(3df,2p) single point energies and B3LYP/6-31 $+\mathrm{G}(\mathrm{d}, \mathrm{p})$ ZPVE corrections, enthalpies and entropies.

dSolvation energies in a water polar dielectric calculated using the refined PCM model [14].

eRelative free energies for protonated adenine tautomers in water.

${ }^{\mathrm{f}}$ The values in parentheses are from calculations that used the older PCM model [15].

we have obtained optimized structures and relative energies of clusters of $1^{+}, 3^{+}, 7^{+}$, and $10^{+}$with one water molecule, and also isomeric clusters of $\mathbf{1}^{+}$and $3^{+}$ with two water molecules. The optimized structures are shown in Figures 2 and 3 . The first water molecule solvating $\mathbf{1}^{+}$is chelated between the $\mathrm{N}-1-\mathrm{H}$ proton and the syn-oriented hydrogen atom of the amino group in the most stable cluster $1 \mathrm{a}^{+}$. Other clusters, e.g., those water-solvated at N-10 and N-7 (1. $\left.\mathbf{b}^{+}\right)$and at N-9 $\left(\mathbf{1 c}^{+}\right)$
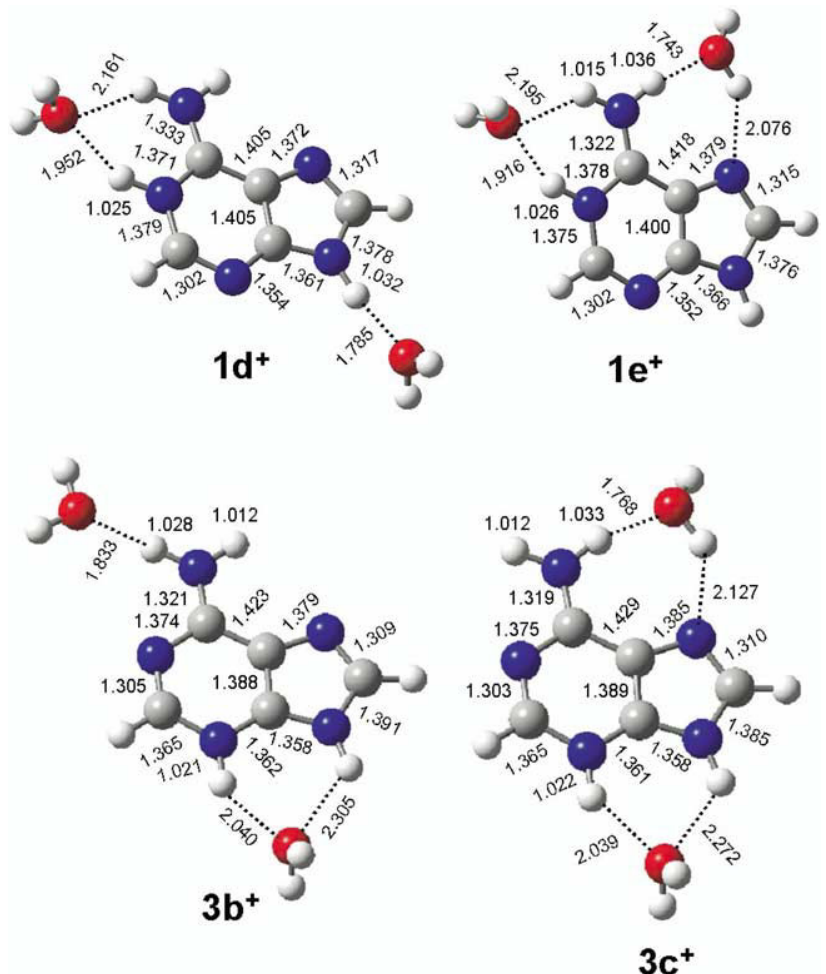

Figure 3. B3LYP/6-31 $+\mathrm{G}(\mathrm{d}, \mathrm{p})$ optimized structures of protonated [adenine $+2 \mathrm{H}_{2} \mathrm{O}$ ] clusters.
Table 2. Relative and dissociation energies of protonated [adenine $+\mathrm{H}_{2} \mathrm{O}$ ] clusters

\begin{tabular}{lcccc}
\hline & \multicolumn{4}{c}{ Relative and dissociation enthalpies } \\
& \multicolumn{4}{c}{ and free energies } \\
\cline { 2 - 5 } Species/reaction & $\Delta H_{0}$ & $\Delta G_{\mathrm{g}, 298}^{\mathrm{o}}$ & $\Delta G_{\mathrm{g}, 373}^{\mathrm{o}}$ & $\Delta G_{\mathrm{g}, 473}^{\mathrm{o}}$ \\
\hline \hline $\mathbf{1 a}^{+}$ & 0.0 & $0.0(94)^{\mathrm{c}}$ & $0.0(84)$ & $0.0(68)$ \\
$\mathbf{1 b}^{+}$ & 12.5 & $13.8(0.3)$ & $14.3(0.8)$ & $15.0(1.5)$ \\
$\mathbf{1 c}^{+}$ & 12.7 & $8.5(3.0)$ & $6.9(9.2)$ & $4.7(21)$ \\
$\mathbf{3 a}^{+}$ & 9.6 & $8.7(2.7)$ & $8.4(5.5)$ & $8.0(8.9)$ \\
$\mathbf{3 b}^{+}$ & 26 & $26(0.0)$ & $26(0.0)$ & $26(0.1)$ \\
$\mathbf{7 a}^{+}$ & 30 & $30(0.0)$ & $30(0.0)$ & $30(0.0)$ \\
$\mathbf{1 0 a}^{+}$ & 85 & $78(0.0)$ & $77(0.0)$ & $74(0.0)$ \\
$\mathbf{1 a}^{+} \rightarrow \mathbf{1}^{+}+\mathrm{H}_{2} \mathrm{O}$ & 61 & 26 & 17 & 5.2 \\
$\mathbf{3 a}^{+} \rightarrow \mathbf{3}^{+}+\mathrm{H}_{2} \mathrm{O}$ & 59 & 24 & 16 & 3.9 \\
$\mathbf{7 a}^{+} \rightarrow \mathbf{7}^{+}+\mathrm{H}_{2} \mathrm{O}$ & 65 & 29 & 20 & 6.9 \\
$\mathbf{1 0 a}^{+} \rightarrow \mathbf{1 0}^{+}+\mathrm{H}_{2} \mathrm{O}$ & 68 & 34 & 25 & 14 \\
\hline
\end{tabular}

aFrom B3-MP2/6-311 + G(3df,2p) single-point energies + B3LYP/6-31 + $G(d, p) Z P V E$, enthalpies and entropies.

${ }^{\mathrm{b}}$ All energies are in units of $\mathrm{kJ} \mathrm{mol}^{-1}$.

${ }^{\mathrm{c}}$ Percentages at equilibrium.

are less stable than $\mathbf{1 a}^{+}$. Structures $\mathbf{1 b}^{+}$and $\mathbf{1 c}^{+}$are analogous to singly-hydrated water clusters of neutral adenine [27]. The optimized structures of the singlyhydrated clusters $3 a^{+}$and $7 a^{+}$show the water molecule being chelated between the N-3 and N-9, and N-7 and $\mathrm{NH}_{2}$ protons, respectively (Figure 2). Hydrogen bonding in $3 \mathrm{a}^{+}$is analogous to water solvation in the N-3-H, N-9-H tautomers of neutral adenine, where the water oxygen also coordinates protons of the $\mathrm{N}-\mathrm{H}$ bonds [27].

The participation of the sterically proximate $\mathrm{N}-\mathrm{H}$ bonds in hydrogen bonding to water is possibly caused by their substantial polarization in protonated adenine. For example, the $\mathrm{H}-14$ and $\mathrm{N}-10$ atoms in $\mathbf{1 a}^{+}$carry elementary charges of 0.44 and -0.72 (by natural population analysis [28], and the resulting bond dipole interacts with the dipole of the water molecule. In contrast, the optimized structure of $\mathbf{1 0 \mathbf { a } ^ { + }}$ shows coordination of the water oxygen atom to one of the ammonium protons, whereas the water protons are not coordinated to the neighboring adenine nitrogen atoms $(\mathrm{N}-1$ or N-7). This is understandable from the NPA local

Table 3. Relative energies of protonated [adenine $+2 \mathrm{H}_{2} \mathrm{O}$ ] clusters

\begin{tabular}{|c|c|c|c|c|}
\hline \multirow[b]{2}{*}{ Species } & \multicolumn{4}{|c|}{$\begin{array}{l}\text { Relative and dissociation enthalpies } \\
\text { and free energies }{ }^{a, b}\end{array}$} \\
\hline & $\Delta H_{0}$ & $\Delta G_{\mathrm{g}, 298}^{\circ}$ & $\Delta G_{\mathrm{g}, 373}^{\circ}$ & $\Delta G_{\mathrm{g}, 473}^{\mathrm{o}}$ \\
\hline $\mathbf{1 d}^{+}$ & 0.2 & $0.0(90)^{\mathrm{c}}$ & $0.0(95)$ & $0.0(96)$ \\
\hline $1 e^{+}$ & 0.0 & $5.6(9.2)$ & $7.8(4)$ & $10.5(1.4)$ \\
\hline $3 \mathbf{b}^{+}$ & 13.9 & $11.5(0.8)$ & $10.8(1)$ & $9.4(2.2)$ \\
\hline $3 c^{+}$ & 14.2 & $19.1(0.0)$ & $20.9(0)$ & $23.1(0.0)$ \\
\hline $1 d^{+} \rightarrow 1 a^{+}+\mathrm{H}_{2} \mathrm{O}$ & 45 & 15 & 7.8 & -2.1 \\
\hline $\mathbf{3} \mathbf{b}^{+} \rightarrow \mathbf{3} \mathbf{a}^{+}+\mathrm{H}_{2} \mathrm{O}$ & 41 & 12 & 5.4 & -3.5 \\
\hline
\end{tabular}

${ }^{\text {a }}$ From B3-MP2/6-311 + G(3df,2p) single-point energies + B3LYP/6-31 + $G(d, p)$ ZPVE enthalpies and entropies.

bIn units of $\mathrm{kJ} \mathrm{mol}^{-1}$.

cPercentages at equilibrium. 


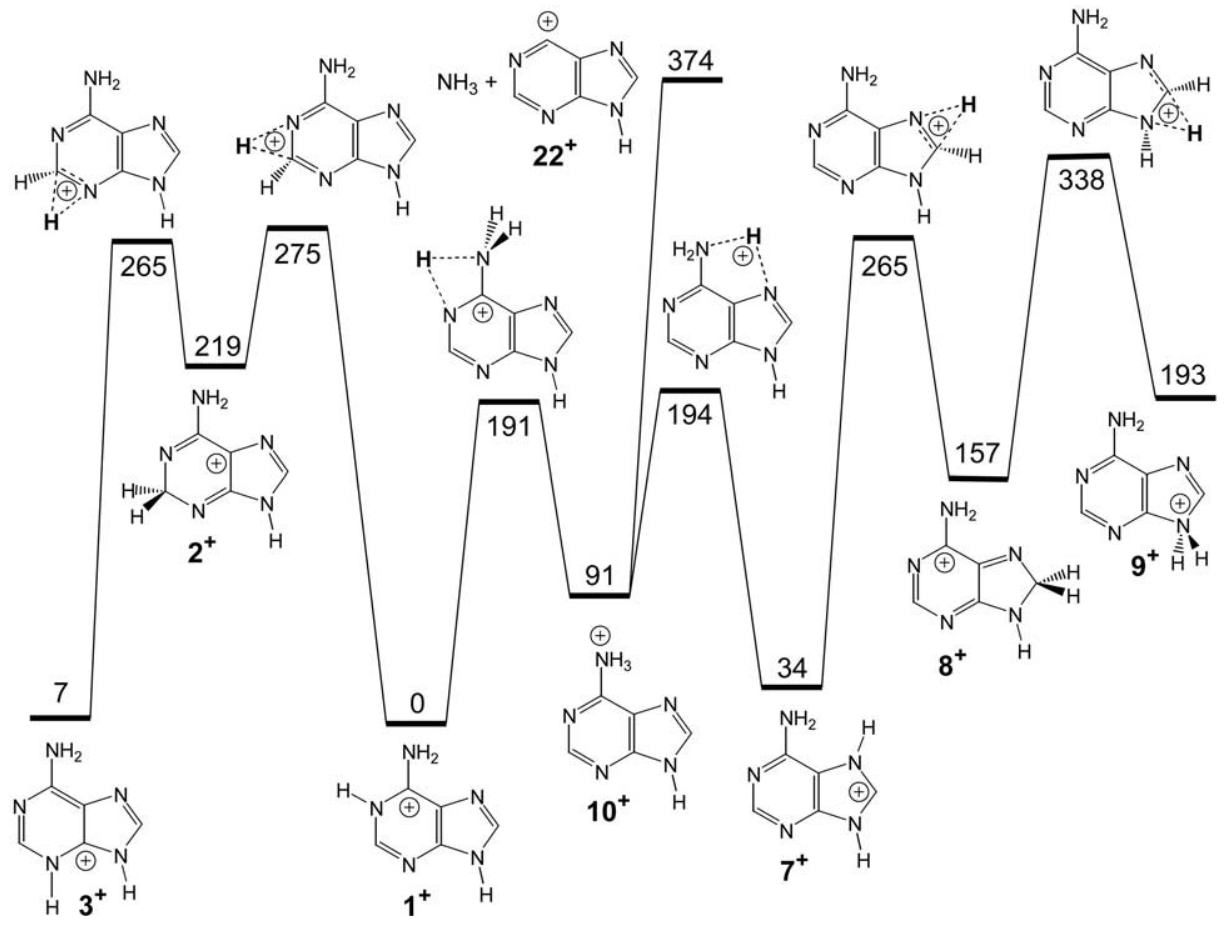

Scheme 1

charges in $\mathbf{1 0 a ^ { + }}$ that show substantial accumulation of positive charge within the $\mathrm{NH}_{3}$ group $(+0.65)$. This results in a tight hydrogen bonding to the water oxygen (at $1.648 \AA \mathrm{O}-\mathrm{H}-14$ distance, Figure 2). A decrease of this ion-dipole interaction upon stretching the $\mathrm{O}-\mathrm{H}-14$ distance apparently would not be compensated by a weak dipole-dipole interaction between one of the water protons and $\mathrm{N}-1$ or N-7 in chelated structures.

Cluster $\mathbf{1 a}^{+}$is calculated to be thermodynamically stable $\left(\Delta G_{\text {dis }}>0\right)$ in the typical range of temperatures used in electrospray ionization (Table 2). However, when the reduced partial pressure of the solvent in the ion transfer system ( 0.5 torr) and the temperature are taken into account, the cluster is predicted to dissociate. For example, at $373 \mathrm{~K}$, a dissociation of $\mathbf{1 a}^{+}$to $\mathbf{1}^{+}$and

Table 4. Transition state energies for $\mathrm{H}$-atom migrations in protonated adenine

\begin{tabular}{lrrrrr}
\hline & \multicolumn{5}{c}{ Transition state energy $^{\text {a }}$} \\
\cline { 2 - 6 } \multicolumn{1}{c}{ Ion } & $\begin{array}{c}\text { B3LYP } \\
\text { 6-31 }+\end{array}$ & B3LYP & MP2 & B3-MP2 & CCSD(T) \\
\cline { 2 - 6 } & G(d,p) & \multicolumn{4}{c}{$6-311+$ G(3df,2p) } \\
\hline \hline $\mathbf{1}^{+}$ & 0 & 0 & 0 & 0 & 0 \\
TS $(\mathbf{1} \rightarrow \mathbf{2})$ & 278 & 279 & 271 & 275 & 285 \\
TS $(\mathbf{1} \rightarrow \mathbf{1 0})$ & 191 & 198 & 184 & 191 & 191 \\
TS $(\mathbf{2} \rightarrow \mathbf{3})$ & 265 & 266 & 264 & 265 & 272 \\
TS $(\mathbf{1 0} \rightarrow \mathbf{7})$ & 198 & 203 & 184 & 194 & 193 \\
TS $(\mathbf{7} \rightarrow \mathbf{8})$ & 256 & 257 & 272 & 265 & 264 \\
TS $(\mathbf{8} \rightarrow \mathbf{9})$ & 336 & 338 & 338 & 338 & 342 \\
TS $(\mathbf{1} \rightarrow \mathbf{1 7})$ & 324 & 328 & 317 & 323 & 317 \\
\hline
\end{tabular}

an units of $\mathrm{kJ} \mathrm{mol}^{-1}$, including zero-point vibrational corrections. water has a $\mathrm{K}_{\mathrm{eq}}=3.9 \times 10^{-3}$, which results in a $\left[\mathbf{1}^{+}\right] /\left[\mathbf{1 a}^{+}\right]=\mathrm{K}_{\mathrm{eq}} \times(760 / 0.5)=5.9$ equilibrium ratio, indicating $\sim 85 \%$ dissociation. The same ratio is $\sim 400$ at $473 \mathrm{~K}$, indicating a complete dissociation of the cluster. This is consistent with the experimental data that showed no solvent clusters in electrospray mass spectra of adenine obtained with heated transfer capillary at 423-453 K [20]. Likewise, clusters $3 \mathbf{a}^{+}, \mathbf{7 a ^ { + }}$, and $\mathbf{1 0 a ^ { + }}$ are thermodynamically stable against loss of water at 298$473 \mathrm{~K}$, but are predicted to dissociate at $473 \mathrm{~K}$ and low partial pressures of water.

Clusters $3 \mathrm{a}^{+}, 7 \mathrm{a}^{+}$, and $10 \mathrm{a}^{+}$are, in general, less stable than $1 \mathrm{a}^{+}$, and their relative stabilities follow the same order as those of the respective protonated adenine tautomers $\mathbf{1}^{+}-\mathbf{1 0}^{+}$(Table 2). This indicates that the most stable $\mathrm{N}$-1-protonated tautomer $\mathbf{1}^{+}$is also the most stable structure when solvated by one water molecule in an intermediate cluster during desolvation. At a 298 K equilibrium, $\mathbf{1 a}^{+}-\mathbf{1} \mathbf{c}^{+}$are calculated to constitute $97 \%$ of all singly hydrated clusters.

$\mathrm{N}-1$ is also calculated to be the preferred protonation site in gas-phase clusters of protonated adenine with two water molecules. Optimized structures were obtained for several doubly hydrated clusters (Figure 3), and their thermodynamic properties are summarized in Table 3 . The most stable structure $\mathbf{1 d}^{+}$preserves coordination to $\mathrm{N}-1-\mathrm{H}$ and $\mathrm{N}-10-\mathrm{H}$ by the first water molecule, whereas the second water is hydrogen bonded to $\mathrm{N}-9-\mathrm{H}$ (Figure 3). An isomer, $\mathbf{1 e}^{+}$, is a local energy minimum that has the second water molecule hydrogen-bonded to $\mathrm{N}-10-\mathrm{H}$ and $\mathrm{N}-7$, which results in a slightly less stable configuration. Two clusters of $3^{+}$ 


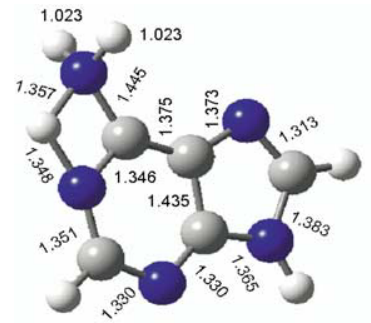

$\mathrm{TS}(1 \rightarrow 10)$

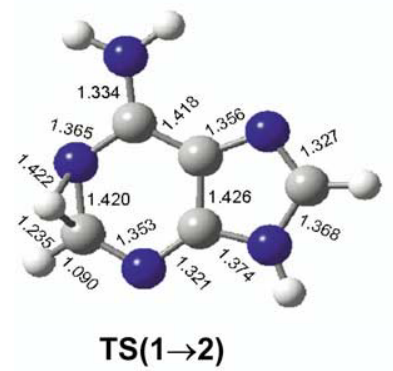

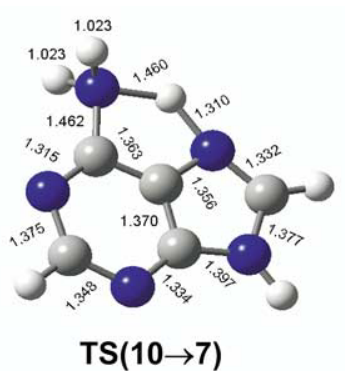

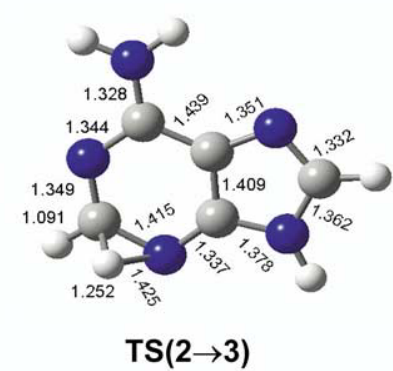

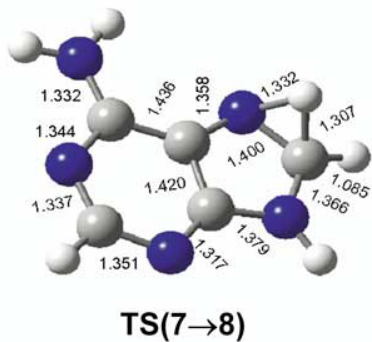

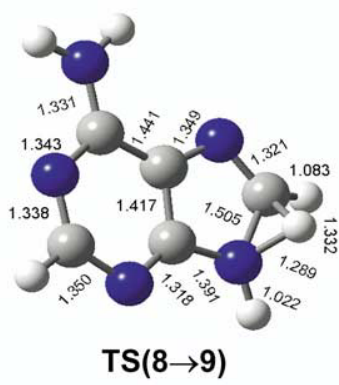

Figure 4. B3LYP/6-31 $+\mathrm{G}(\mathrm{d}, \mathrm{p})$ optimized structures of transition states for proton migrations.

were found as local energy minima, $3 \mathbf{b}^{+}$and $3 \mathbf{c}^{+}$, that are both less stable than $\mathbf{1} \mathbf{b}^{+}$and $\mathbf{1} \mathbf{c}^{+}$. At equilibrium, $97-99 \%$ of [adenine $+2 \mathrm{H}_{2} \mathrm{O}$ ] clusters consist of $\mathrm{N}-1-$ protonated structures. The second water molecule is bound $16-18 \mathrm{~kJ} \mathrm{~mol}^{-1}$ less strongly than the first one, and the doubly-solvated complexes become thermodynamically unstable at $473 \mathrm{~K}$. Even at $298 \mathrm{~K}$, the $\Delta G_{\mathrm{g}}^{\mathrm{o}}$ values (Table 3) indicate that the doubly-hydrated complexes substantially dissociate when the water partial pressure drops to 0.5 torr.

In summary, $\mathrm{N}-1$-protonated adenine $\mathbf{1}^{+}$is the most stable tautomer in aqueous solution, water clusters, and the gas phase. Protonation in water under equilibrium conditions is predicted to form $90-97 \%$ of $\mathbf{1}^{+}$as the most stable tautomer whose isomerization to other tautomers during transition to the gas phase is thermodynamically disfavored in all intermediate stages. The logical conclusion is that the predominant majority of protonated adenine ions produced by electrospray have structure $\mathbf{1}^{+}$.

\section{Proton Migrations in Protonated Adenine in the Gas Phase}

Loss of a hydrogen atom, which is the dominant dissociation of $\mathbf{1}^{+}$upon CAD at $\mathrm{keV}$ collision energies, is accompanied by extensive though incomplete randomization of all hydrogen atoms in the ion [3]. Our previous calculations showed that the loss of an $\mathrm{H}$ atom is a highly endothermic dissociation that requires $415 \mathrm{~kJ}$ $\mathrm{mol}^{-1}$ at the thermochemical threshold of the lowestenergy product, which is the adenine cation-radical [3]. In addition, complete-active space (CASSCF) calculations indicated that the dissociation of the $\mathrm{N}-1-\mathrm{H}$ bond in $\mathbf{1}^{+}$is continuously endothermic and proceeds with- out a reverse potential energy barrier. A question arises of how the $\mathrm{N}-1-\mathrm{H}$ bond dissociation in $\mathbf{1}^{+}$competes with intramolecular hydrogen migrations that scramble the $\mathrm{H}$ atoms among positions $\mathrm{N}-1, \mathrm{C}-2, \mathrm{~N}-10, \mathrm{C}-8$, and $\mathrm{N}-9$. To address this issue, we have now obtained the potential energy barriers for transition states for several relevant 1,2-1,3-, and 1,4-hydrogen migrations. A sequence of such migrations represents a plausible mechanism for scrambling all hydrogen atoms in $\mathbf{1}^{+}$. The transition states for $\mathrm{H}$-atom migrations from B3-MP2 calculations are shown schematically in Scheme $\mathbf{1}$ and briefly discussed in text. The TS energies obtained at other levels of theory are summarized in Table 4 . Starting clockwise from $\mathbf{1}^{+}$, a 1,3-migration through $\mathrm{TS}(\mathbf{1} \rightarrow \mathbf{1 0})$ produces isomer $\mathbf{1 0}^{+}$. TS $(\mathbf{1} \rightarrow \mathbf{1 0})$ (Figure 4 ) is the lowest-energy transition-state for hydrogen migrations in protonated adenine at $\mathrm{E}_{\mathrm{TS}}=191 \mathrm{~kJ} \mathrm{~mol}^{-1}$ above $1^{+}$. Ion $10^{+}$can undergo a consecutive $1,4-\mathrm{H}-$ migration through $\mathrm{TS}(\mathbf{1 0} \rightarrow \mathbf{7})$ to form $\mathbf{7}^{+}$, which can further isomerize to $8^{+}$through $\operatorname{TS}(7 \rightarrow 8)$. A further 1,2- $\mathrm{H}$ migration from $8^{+}$to $9^{+}$faces a high-energy TS $(8 \rightarrow 9)$ at $\mathrm{E}_{\mathrm{TS}}=338 \mathrm{~kJ} \mathrm{~mol}^{-1}$ relative to $\mathbf{1}^{+}$.

Starting counter-clockwise from $\mathbf{1}^{+}$, a 1,2 -migration through TS $(\mathbf{1} \rightarrow \mathbf{2})$ (Figure 4) produces isomer $\mathbf{2}^{\mathbf{+}}$, which can further isomerize by a 1,2-H migration through TS $(2 \rightarrow 3)$ to the more stable isomer $3^{+}$. We could not find a transition-state for a 1,3- $\mathrm{H}$ migration from $\mathrm{N}-3$ to N-9, possibly because of the rigidity of the adenine skeleton that prevents N-3 and N-9 from getting at a distance allowing $\mathrm{H}$-atom transfer. A series of 1,2- $\mathrm{H}$ migrations may also be possible, e.g., N-3 $\rightarrow \mathrm{C}-4$, and C-4 $\rightarrow$ N-9, that would complete the proton ring walk. However, C-4-protonated adenine $\left(4^{+}\right)$is $252 \mathrm{~kJ} \mathrm{~mol}^{-1}$ less stable than $\mathbf{1}^{+}$, indicating a high-energy barrier for the isomerization. Because C-4 carries no hydrogen atom, H- 


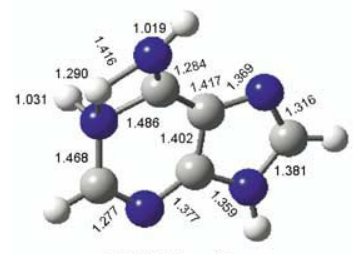

$\mathrm{TS}(17 \rightarrow 1)$

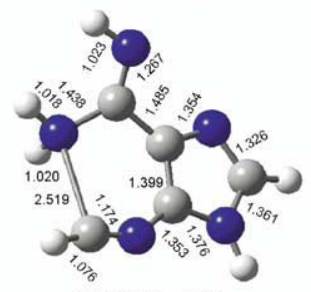

TS $(13 \rightarrow 14)$

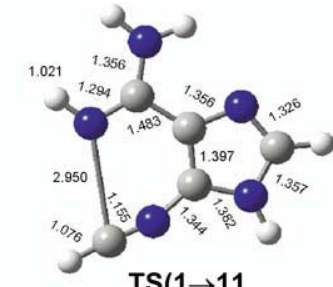

$\mathrm{TS}(1 \rightarrow 11$

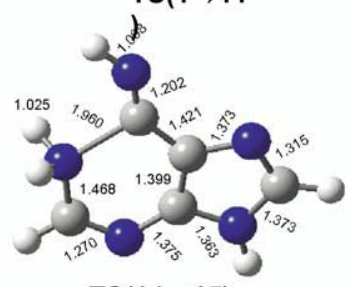

$\mathrm{TS}(14 \rightarrow 15)$
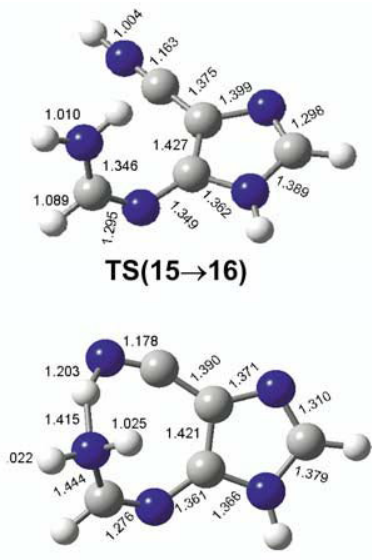

$\mathrm{TS}(16 \rightarrow 18)$

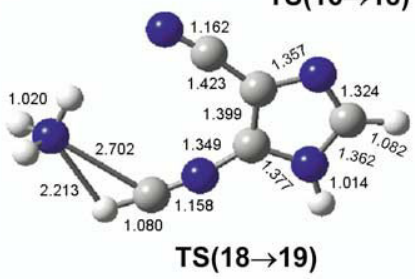

Figure 5. B3LYP/6-31 $+\mathrm{G}(\mathrm{d}, \mathrm{p})$ optimized structures of transition states for $\mathrm{N}-1 / \mathrm{N}-10$ exchange.

migration through C-4 does not increase the pool of hydrogen atoms involved in $\mathrm{H}$-atom scrambling in protonated adenine. The important reference energy points are the dissociation thresholds for loss of $\mathrm{H}$ forming adenine cation-radical $\left(415 \mathrm{~kJ} \mathrm{~mol}^{-1}\right.$ above $\left.\mathbf{1}^{+}\right)$ and elimination of ammonia. The latter is at $374-380 \mathrm{~kJ}$ mo1 ${ }^{-1}$ above $\mathbf{1}^{+}$, depending on the product cation, as discussed in more detail in the next section.

The TS energies indicate that $\mathrm{H}$-atom migrations in $\mathbf{1}^{+}$are possible at ion internal energies well below the dissociation thresholds for loss of $\mathrm{H}$ and elimination of ammonia. Starting from $\mathbf{1}^{+}$, a single reversible pass through $\mathrm{TS}(\mathbf{1} \rightarrow \mathbf{2})$ would randomize the $\mathrm{N}-1$ and $\mathrm{C}-2$ hydrogen atoms. Randomization of $\mathrm{H}$ atoms at positions $\mathrm{N}-10, \mathrm{C}-8$, and $\mathrm{N}-9$ would require several reversible consecutive steps in the clock-wise pathway. The effect this may have on the kinetics of competitive dissociations and $\mathrm{H}$-atom migrations is discussed later in the section on RRKM kinetics.

\section{Mechanisms for N-1 and N-10 Exchange in Loss of Ammonia and Formation of $\mathrm{NH}_{4}^{+}$}

Elimination of $\mathrm{N}-1$ as ammonia or $\mathrm{NH}_{4}^{+}$must involve opening of the pyrimidine ring and multiple hydrogen

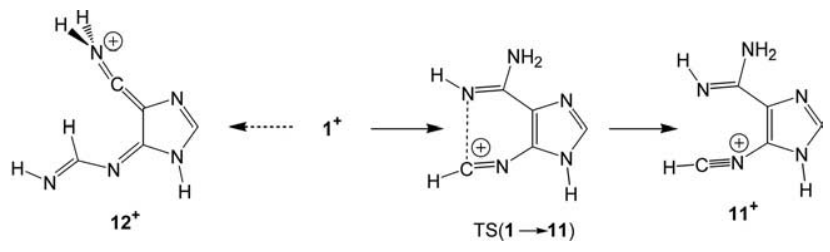

Scheme 2 transfers. Ring openings in $\mathbf{1}^{+}$were investigated for dissociations of the N-1-C-2 and N-1-C-6 bonds leading to intermediates $\mathbf{1 1}^{+}$and $\mathbf{1 2}^{+}$, respectively (Scheme 2, Figure 5). Both these dissociations are substantially endothermic at 257 and $410 \mathrm{~kJ} \mathrm{~mol}^{-1}$, for $\mathbf{1 1}^{+}$ and $\mathbf{1 2}^{+}$, respectively (Table 5). Intermediate $\mathbf{1 2}^{+}$is above the dissociation threshold for loss of ammonia and its reactions were not studied further. Intermediate $\mathbf{1 1}^{+}$is a very shallow potential energy minimum that becomes $1 \mathrm{~kJ} \mathrm{~mol}^{-1}$ unstable with respect to ring closure through $\mathrm{TS}(\mathbf{1 1} \rightarrow \mathbf{1})$ when zero-point corrections are included. Hence, ion $\mathbf{1 1}^{+}$can be considered a ledge on the potential energy surface for $\mathbf{1}^{+}$dissociations. Rotation of the amidine group in $\mathbf{1 1}^{+}$about the C-5 - C- 6 bond is endothermic and leads to another intermediate $\mathbf{1 3}^{+}$at $317 \mathrm{~kJ} \mathrm{~mol}^{-1}$ above $\mathbf{1}^{+}$(Scheme 3 , Figure 6 . Note that the $\mathrm{N}-1$ imine group in both $\mathbf{1 1}^{+}$and $13^{+}$has an unfavorable syn-configuration that does not allow hydrogen migration from the N-10 amino group. Syn-anti flipping of the imine hydrogen in $\mathbf{1 1}^{+}$is endothermic to form anti-11 ${ }^{+}$at $303 \mathrm{~kJ} \mathrm{~mol}^{-1}$. Syn-anti flipping of the imine hydrogen in $13^{+}$to anti-13 ${ }^{+}$is $11 \mathrm{~kJ}$ $\mathrm{mol}^{-1}$ exothermic, but shows a TS at $394 \mathrm{~kJ} \mathrm{~mol}^{-1}$ relative to $\mathbf{1}^{+}$which is above the dissociation threshold for loss of ammonia.

A lower-energy TS (Figure 6) was found at $339 \mathrm{~kJ}$ $\mathrm{mol}^{-1}$ for a ring closure in $13^{+}$to form ion $14^{+}$in which the former $\mathrm{N}-10$ is now in a ring position and $\mathrm{N}-1$ is in the exocyclic imine group (Scheme 3). Upon syn-anti flipping of the imine group in $\mathbf{1 4}^{+}$, an exothermic ring opening occurs that breaks the $\mathrm{C}-6-\mathrm{N}-10$ bond to form intermediate $15^{+}$at $191 \mathrm{~kJ} \mathrm{~mol}^{-1}$ above $\mathbf{1}^{+}$. The TS for $\mathbf{1 4}^{+} \rightarrow \mathbf{1 5}^{+}$(Figure 5) is only $1 \mathrm{~kJ} \mathrm{~mol}^{-1}$ above $\mathbf{1 4}^{+}$ suggesting that this ion is dynamically unstable when 
Table 5. Relative energies for intermediates and transition states

\begin{tabular}{|c|c|c|c|c|c|}
\hline \multirow{4}{*}{ Ion } & \multicolumn{5}{|c|}{ Relative Energy } \\
\hline & \multirow{3}{*}{$\begin{array}{c}\text { B3LYP } \\
6-31+G(d, p)\end{array}$} & B3LYP & MP2 & B3-MP2 & $\operatorname{CcsD}(T)$ \\
\hline & & & & & \\
\hline & & \multicolumn{4}{|c|}{$6-311+G(3 d f, 2 p)$} \\
\hline $1^{+}$ & 0 & 0 & 0 & 0 & 0 \\
\hline $10^{+}$ & 95 & 101 & 82 & 91 & 87 \\
\hline $11^{+}$ & 264 & 258 & 256 & 257 & 257 \\
\hline anti-11 $^{+}$ & 313 & 302 & 304 & 303 & 304 \\
\hline $\mathrm{TS}(\mathbf{1} \rightarrow \mathbf{1 1})$ & 264 & 257 & 255 & 256 & 256 \\
\hline $12^{+}$ & 385 & 379 & 442 & 410 & 396 \\
\hline $13^{+}$ & 324 & 316 & 317 & 317 & 315 \\
\hline anti-13 ${ }^{+}$ & 313 & 307 & 306 & 306 & 304 \\
\hline $\mathrm{TS}(1 \rightarrow a n t i-13)$ & 323 & 318 & 320 & 319 & 313 \\
\hline $\mathrm{TS}(\mathbf{1 1} \rightarrow a n t i-11)$ & 374 & 365 & 372 & 368 & 375 \\
\hline $\mathrm{TS}(13 \rightarrow a n t i-13)$ & 398 & 390 & 399 & 394 & 399 \\
\hline $\mathrm{TS}(a n t i-13 \rightarrow a n t i-11)$ & 498 & 489 & 483 & 486 & 492 \\
\hline $\mathrm{TS}(13 \rightarrow 14)$ & 341 & 336 & 341 & 339 & 332 \\
\hline $14^{+}$ & 262 & 261 & 259 & 260 & 250 \\
\hline $\mathrm{TS}(\mathbf{1 4} \rightarrow \mathbf{1 5})$ & 260 & 259 & 263 & 261 & 258 \\
\hline $15^{+}$ & 184 & 175 & 208 & 191 & 198 \\
\hline $\mathrm{TS}(15 \rightarrow 16)$ & 190 & 178 & 201 & 190 & 195 \\
\hline $16^{+}$ & 188 & 177 & 209 & 193 & 200 \\
\hline $\mathrm{TS}(16 \rightarrow 17)$ & 259 & 257 & 265 & 261 & 260 \\
\hline $17^{+}$ & 230 & 232 & 227 & 229 & 218 \\
\hline $\mathrm{TS}\left(\mathbf{1 7} \rightarrow \mathbf{1}^{\prime}\right)$ & 324 & 328 & 317 & 323 & 317 \\
\hline $18^{+}$ & 245 & 239 & 228 & 234 & 232 \\
\hline $\mathrm{TS}(16 \rightarrow 18)$ & 273 & 268 & 267 & 267 & \\
\hline $19^{+}$ & 247 & 243 & 231 & 237 & 234 \\
\hline $\mathrm{TS}(18 \rightarrow 19)$ & 324 & 314 & 307 & 311 & 315 \\
\hline $20^{+}+\mathrm{NH}_{3}$ & 393 & 376 & 373 & 375 & 380 \\
\hline $22^{+}+\mathrm{NH}_{3}$ & 380 & 369 & 379 & 374 & 376 \\
\hline $\mathrm{NH}_{4}^{+}+21$ & 333 & 331 & 322 & 326 & 317 \\
\hline $23^{+}$ & 291 & 290 & 291 & 291 & 296 \\
\hline $\mathrm{TS}(10 \rightarrow 23)$ & 362 & 354 & 365 & 359 & 362 \\
\hline $24^{+}$ & 334 & 330 & 337 & 334 & 336 \\
\hline
\end{tabular}

aln units of $\mathrm{kJ} \mathrm{mol}^{-1}$ including B3LYP/6-31 + G(d,p) ZPVE corrections.

produced by the exothermic ring closure through TS(13 $\rightarrow$ 14). Intermediate $15^{+}$undergoes a practically barrierless rotation of the imine group to an anti-isomer $\left(\mathbf{1 6}^{+}\right)$which can reform the pyrimidine ring through $\mathrm{TS}(16 \rightarrow 17)$ (Figure 5) at $\mathrm{E}_{\mathrm{TS}}=261 \mathrm{~kJ} \mathrm{~mol}^{-1}$ to produce ion $\mathbf{1 7}^{+}$(Scheme 4). Finally, a 1,3-hydrogen migration from the ring $\mathrm{N}-10-\mathrm{H}_{2}$ group in $17^{+}$through $\mathrm{TS}(\mathbf{1 7} \rightarrow$ $\left.\mathbf{1}^{\prime}\right)$ at $\mathrm{E}_{\mathrm{TS}}=323 \mathrm{~kJ} \mathrm{~mol}^{-1}$ (Figure 5) concludes the N-1 and $\mathrm{N}-10$ swap in ion $\mathbf{1}^{\prime+}$ (Scheme 4 ).

The energies for the intermediates and TS along the isomerization pathway for converting $\mathbf{1}^{+}$to $\mathbf{1}^{\prime+}$ are summarized in Table 5 . The potential energy surface shows three kinetically important points. The highenergy $\mathrm{TS}(\mathbf{1 3} \rightarrow \mathbf{1 4})$ and $\mathrm{TS}\left(\mathbf{1 7} \rightarrow \mathbf{1}^{\prime}\right)$ at 339 and $323 \mathrm{~kJ}$

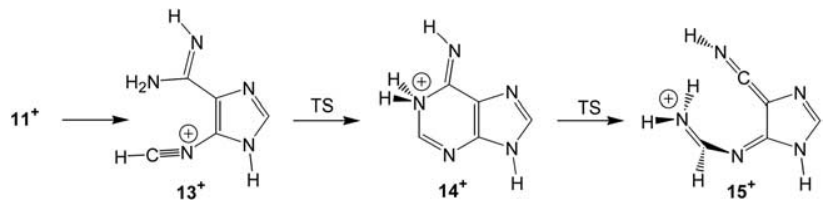

Scheme 3 $\mathrm{mol}^{-1}$, respectively, (Table 5) represent the bottlenecks for the $\mathbf{1}^{+} \rightarrow \mathbf{1}^{\prime+}$ isomerization. Note that these TS have energies that are above that for N-1 $\rightarrow$ N-10 H-migration, so that ions $\mathbf{1}^{+}$that undergo nitrogen swap through the $\mathbf{1}^{+} \rightarrow \mathbf{1}^{\prime+}$ pathway have sufficient internal energy to isomerize to $\mathbf{1 0}^{+}$en route to elimination of ammonia. However, the energy threshold for the elimination of ammonia is above the highest-energy TS in the $\mathbf{1}^{+} \rightarrow \mathbf{1}^{\prime+}$ isomerization pathway. In other words, a fraction of $\mathbf{1}^{+}$can exchange the N-1 and N-10 positions before losing ammonia. The third kinetically important point is the practically isoenergetic intermediates $15^{+}$ and $16^{+}$that can be considered as two fluxional forms of a single species. In contrast, intermediates $\mathbf{1 1}^{+}, \mathbf{1 3}^{+}$, $14^{+}$, and $17^{+}$exist as shallow potential energy minima or ledges on the potential energy surface and are therefore kinetically less important. This feature plays a role in the kinetics of the $\mathbf{1}^{+} \rightarrow \mathbf{1}^{\prime+}$ isomerization that will be addressed later in the pertinent section.

The isomerization pathway revealed by the present calculations differs from the mechanism suggested by Nelson and McCloskey [5]. Those authors considered 


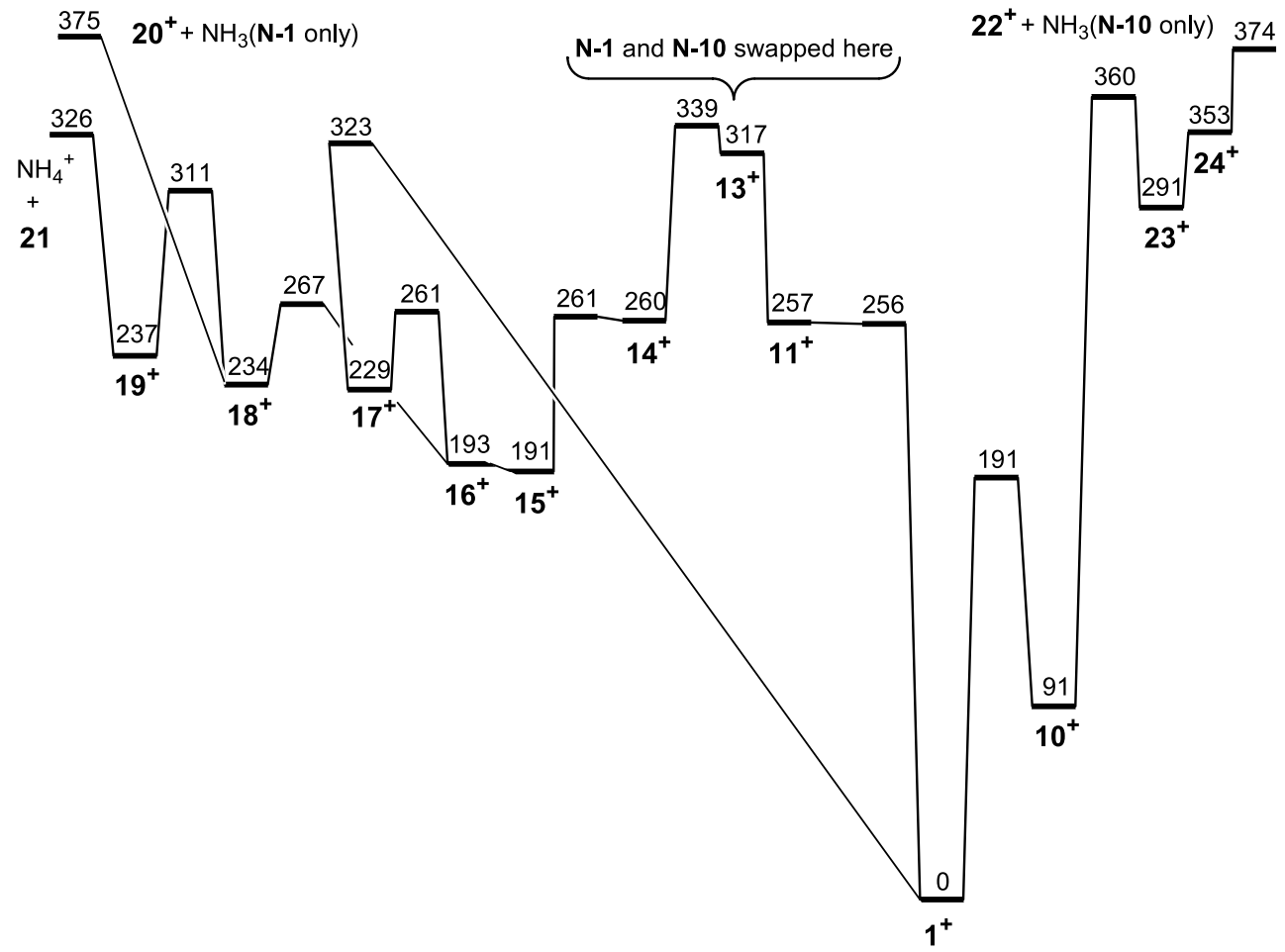

Figure 6. Potential energy surface for $\mathrm{N}-1 / \mathrm{N}-10$ swapping isomerizations in $\mathbf{1}^{+}$. The energies in $\mathrm{kJ}$ $\mathrm{mol}^{-1}$ are from B3-MP2/6-311 + G(3df,2p) + ZPVE calculations and are plotted relative to $\mathbf{1}^{+}$.

H-migration in what they thought was a stable, openring isomer of protonated adenine, e.g., $11^{+}, \mathbf{1 3}^{+}$, or their anti-isomers. We have obtained the TS for $\mathrm{H}$ migration in anti-13 ${ }^{+} \rightarrow$ anti-11 ${ }^{+}$that would swap N-1 and N-10 according to the Nelson-McCloskey mechanism (Scheme 6). However, the TS appears at a very high-energy (486 kJ mol${ }^{-1}$ relative to $\mathbf{1}^{+}$), which indicates that this pathway could not compete with other isomerizations, e.g., $\mathbf{1 3} \rightarrow \mathbf{1 4}$, nor with a loss of ammonia through $\mathbf{1}^{+} \rightarrow \mathbf{1 0}^{+}$which would involve only N-10. The present calculations further indicate that open-ring isomers of $\mathbf{1}^{+}$are all high-energy species that can exist only as transient intermediates in multi-step dissociations, but are not significantly populated at equilibrium with $\mathbf{1}^{+}$.

An intriguing feature of dissociations of $\mathbf{1}^{+}$, as determined experimentally [5], is the formation of $\mathrm{NH}_{4}^{+}$containing mainly $\mathrm{N}-1$, not $\mathrm{N}-10$. This indicates an isomerization/dissociation pathway starting from $\mathbf{1}^{+}$but excluding the steps that result in $\mathrm{N}-1 / \mathrm{N}-10$ exchange such as those in the elimination of ammonia. An energetically plausible mechanism is shown in Scheme 6. It starts from intermediate $16^{+}$that can

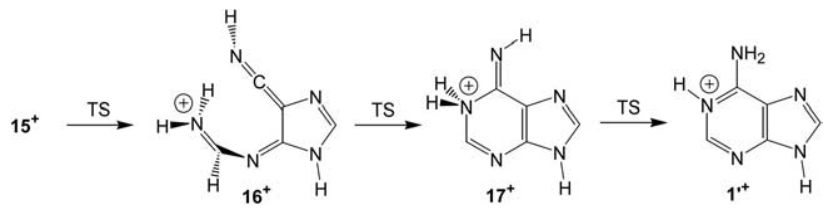

Scheme 4 be accessed directly from $\mathbf{1}^{+}$by inverse hydrogen migration from the $\mathrm{N}-10$ amino group unto $\mathrm{N}-1, \mathbf{1}^{+} \rightarrow$ $17^{+}$, followed by exothermic ring opening to $16^{+}$. Note that these steps do not cause $\mathrm{N}-1 / \mathrm{N}-10$ exchange. Intermediate $16^{+}$undergoes isomerization by $\mathrm{H}$-atom migration to form ion $\mathbf{1 8}^{+}$. The latter further rearranges by $\mathrm{NH}_{3}$ migration to form an ion-molecule complex $\left(\mathbf{1 9}^{+}\right)$consisting of $\mathrm{NH}_{4}^{+}$which is hydrogenbonded to isonitrile 21. Complex $19^{+}$can undergo competitive dissociations to $\mathrm{NH}_{4}^{+}$at $326 \mathrm{~kJ} \mathrm{~mol}^{-1}$ threshold energy relative to $\mathbf{1}^{+}$, or by proton transfer and loss of ammonia to form ion $20^{+}$at $375 \mathrm{~kJ} \mathrm{~mol}^{-1}$ threshold energy. The difference between these two threshold energies comes from the difference in the proton affinities of ammonia and isonitrile 21 .

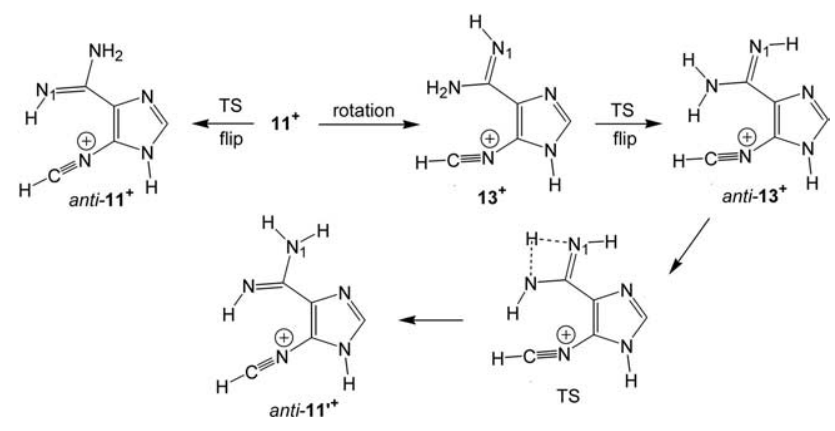

Scheme 5 

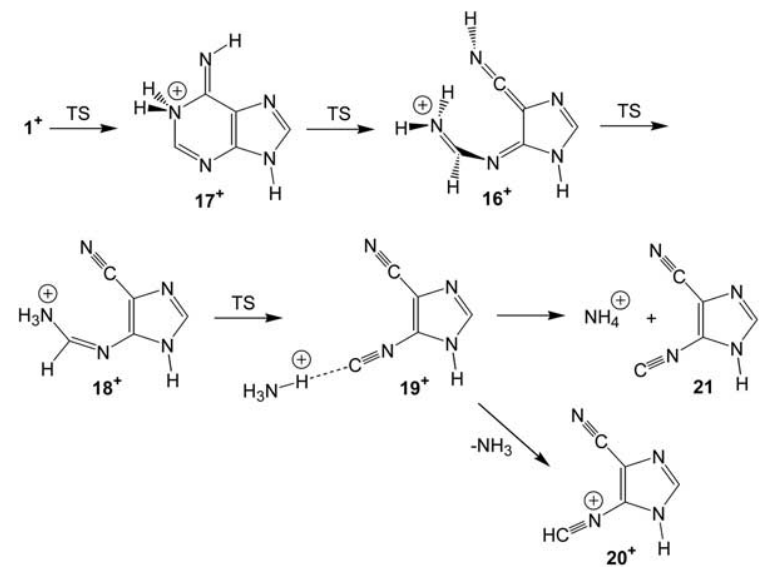

Scheme 6

\section{Dissociation Kinetics}

The B3-MP2 and CCSD(T) potential energy surfaces for the isomerizations and dissociations of protonated adenine provide platforms for the qualitative interpretation of the experimental data obtained from CAD spectra. In particular, the calculated TS and threshold energies indicate that ions possessing internal energies that allow them to dissociate by loss of $\mathrm{H}$, ammonia, and formation of $\mathrm{NH}_{4}^{+}$can also isomerize by ring opening/closure and hydrogen migrations that result in scrambling of all six hydrogen atoms and $\mathrm{N}-1 / \mathrm{N}-10$ exchange in the dissociating ions and products. We now address the quantitative aspects of these competitive and consecutive reactions by using unimolecular rate constants calculated by RRKM theory. The kinetic scheme for the elimination of ammonia is complicated owing to the number of intermediates along the dissociation pathways, as shown in Figure 6. The overall kinetic scheme, including all intermediates and interconnecting transition states, is practically intractable. However, the hydrogen migrations around the adenine ring can be considered cul-de-sac reactions that are kinetically irrelevant for the branching ratios for the loss of $\mathrm{NH}_{3}$ involving $\mathrm{N}-1$ and $\mathrm{N}-10$. This follows from kinetic analysis and the fact that $\mathbf{1}^{+}$or its $\mathrm{N}$-swapped counterpart $\mathbf{1}^{+}$are nodal species in the branching scheme for dissociations leading to loss of $\mathrm{NH}_{3}$.

With regard to loss of $\mathrm{NH}_{3}$, we will address three pathways. The first one consists of reversible isomerizations resulting in $\mathrm{N}-1 / \mathrm{N}-10$ swapping, $\mathbf{1}^{+} \leftrightarrow \mathbf{1 1}^{+} \leftrightarrow$ $14^{+} \leftrightarrow 15^{+} \leftrightarrow 16^{+} \leftrightarrow 17^{+} \leftrightarrow 1^{\prime+}$. The other two are dissociations of intermediates to $\mathbf{2 0}^{+}+\mathrm{NH}_{3}$ and $\mathbf{2 2}^{+}+$ $\mathrm{NH}_{3}$, respectively. The RRKM rate constants (Figure 7a) for the reversible isomerizations identify $\mathbf{1}^{+} \leftrightarrow \mathbf{1 5}^{+}, \mathbf{1 5}^{+}$ $\leftrightarrow 17^{+}$, and $17^{+} \leftrightarrow 1^{\prime+}$ as the rate determining coupled steps, so that the time- and internal energy-dependent reaction fluxes through these steps, $\mathbf{1}^{+} \leftrightarrow 15^{+} \leftrightarrow 17^{+} \leftrightarrow$ $\mathbf{1}^{\prime+}$, can be rigorously handled by formal kinetics [29]. A factor beyond our kinetic analysis is the uncertainty in the reaction times and conversions to products in the previous CAD experiments $[4,5]$. These were carried out under multiple-collision conditions and so, the terminal ion velocities and hence, the dissociation times are unknown. We estimate that the dissociation times were within a broad range of $100-1000 \mu$ s and for those we calculate the time-dependent populations of $\mathbf{1}^{+}$and $\mathbf{1}^{\prime+}$ as a function of the internal energy of $\mathbf{1}^{+}$which was the initial reactant. We also estimate from the published CAD spectra [4] that about $10 \%$ of precursor ions dissociated by loss of ammonia under those experimental conditions.

Figure $7 \mathrm{~b}$ shows the molar fractions of $\mathbf{1}^{+}$and $\mathbf{1}^{\prime+}$ (with swapped $\mathrm{N}-1$ and $\mathrm{N}-10$ nitrogen atoms) resulting from the kinetic analysis of the $1^{+} \leftrightarrow 15^{+} \leftrightarrow 17^{+} \leftrightarrow 1^{\prime+}$ isomerization, plotted as a function of the ion internal energy and based on $\operatorname{CCSD}(\mathrm{T}) \mathrm{TS}$ energies. The energy and time-dependent molar fractions were calculated using the RRKM rate constants and solving the differential kinetic equations by Laplace transforms; they are plotted for three representative reaction times, $133 \mu \mathrm{s}$, $420 \mu \mathrm{s}$, and $1.33 \mathrm{~ms}$. Calculations using the B3-MP2 energies gave very similar results and need not be discussed separately. Figure 7 shows that the $\mathbf{1} \leftrightarrow \mathbf{1}^{\prime+}$ isomerization exhibits a very substantial kinetic shift [30] that amounts to $>120 \mathrm{~kJ} \mathrm{~mol}^{-1}$. The highest TS energy
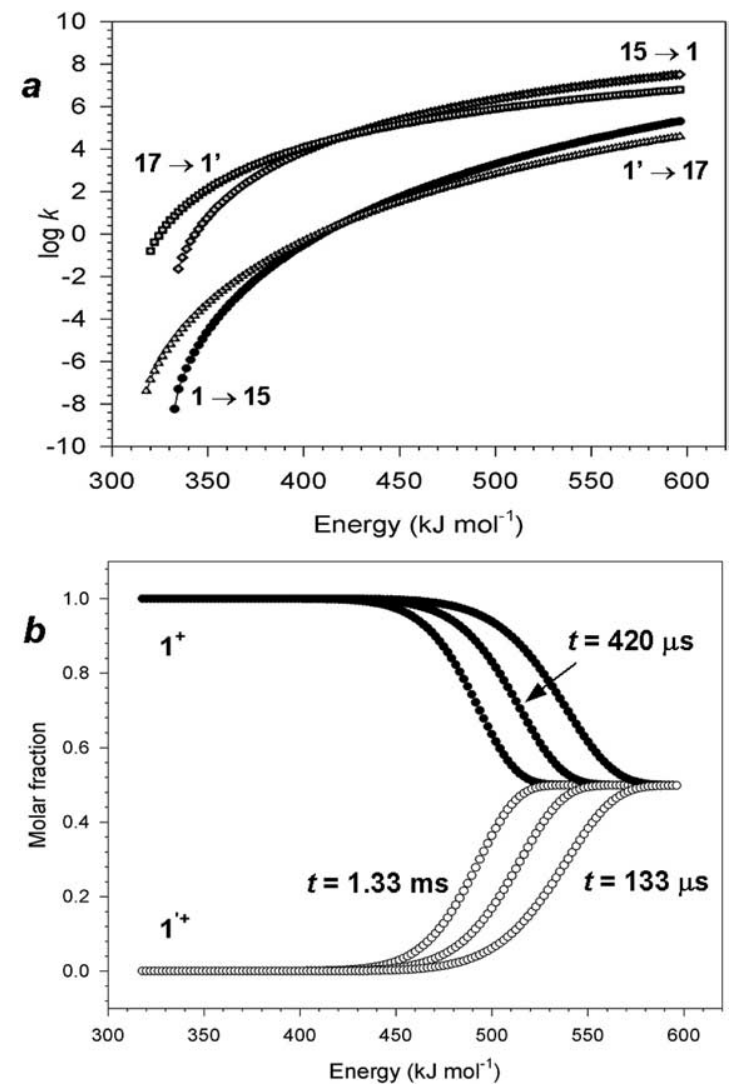

Figure 7. (a) RRKM rate constants $\left(\log k, \mathrm{~s}^{-1}\right.$ ) for reversible isomerizations $\mathbf{1}^{+} \leftrightarrow \mathbf{1 5}^{+}$and $\mathbf{1 7}^{+} \leftrightarrow \mathbf{1}^{\prime+}$ calculated for CCSD(T)/ $6-311+G(3 d f, 2 p)$ TS energies. (b) Energy and time-dependent molar fractions of $\mathbf{1}^{+}$and $\mathbf{1}^{\prime+}$ from RRKM rate constants and formal kinetic analysis of reversible isomerizations of $\mathbf{1}^{+} \leftrightarrow \mathbf{1 5}^{+} \leftrightarrow$ $17^{+} \leftrightarrow \mathbf{1}^{\prime+}$. The reaction times are as indicated. 


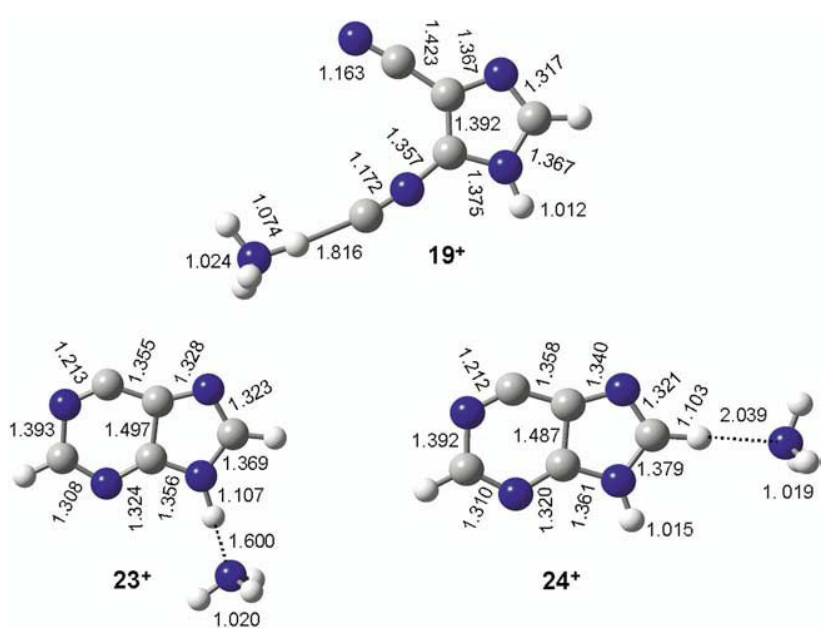

Figure 8. B3LYP/6-31 $+\mathrm{G}(\mathrm{d}, \mathrm{p})$ optimized structures of ionmolecule complexes $19^{+}, 23^{+}$, and $24^{+}$.

for this pathway is at $\mathrm{TS}(\mathbf{1 3} \rightarrow \mathbf{1 4})=332 \mathrm{~kJ} \mathrm{~mol}^{-1}$ relative to $\mathbf{1}^{+}$, yet the formation of $\mathbf{1}^{\prime+}$ becomes significant $(k>10)$ only at internal energies $>450 \mathrm{~kJ} \mathrm{~mol}^{-1}$. To approach the experimentally observed equilibration of $\mathbf{1} \leftrightarrow \mathbf{1}^{\prime+}(44 / 56)$ [5] requires that $\mathbf{1}^{+}$had internal energies greater than 510 and $560 \mathrm{~kJ} \mathrm{~mol}^{-1}$ at reaction times of $1.3 \mathrm{~ms}$ and $133 \mu \mathrm{s}$, respectively. We note that these internal energies are accessible in collisions with argon atoms of $\mathbf{1}^{+}$having $\mathrm{E}_{\mathrm{LAB}}=30 \mathrm{eV}$, where the upper bound of the convertible energy is given by the center of mass energy, $\mathrm{E}_{\mathrm{CM}}=30 \times 40 /(40+136)=6.82$ $\mathrm{eV}$ in a single collision. The finding that a slightly greater fraction of ammonia contains $\mathrm{N}-1$ than $\mathrm{N}-10$ points to the participation by a competing channel, e.g., $\mathbf{1}^{+} \leftrightarrow \mathbf{1 7}^{+} \leftrightarrow \mathbf{1 6}^{+} \leftrightarrow \mathbf{1 8}^{+} \rightarrow \mathbf{2 0}^{+}+\mathrm{NH}_{3}$, which involves only N-1. Conversely, the dissociation through the channel $1^{+} \leftrightarrow 10^{+} \leftrightarrow 23^{+} \leftrightarrow 24^{+} \rightarrow 2^{+}+\mathrm{NH}_{3}$ that involves only $\mathrm{N}-10$ when starting from $1^{+}$must be slower than the $\mathrm{N}-1 / \mathrm{N}-10$ exchange to satisfy the experimental data.

Solving the kinetics of the dissociations by loss of ammonia is made difficult by two factors. One is that the final dissociation steps from $18^{+}, \mathbf{1 9}^{+}$, and $24^{+}$are continuously endothermic, and must be treated by appropriate kinetic models, e.g., variational TS theory [19] or the transition-state switching model [31]. This is aggravated by the existence of several shallow local minima on the potential energy surface that correspond to weakly bound ion-dipole complexes of $2^{+}$and ammonia, such as structures $\mathbf{1 9}^{+}, \mathbf{2 3}^{+}$, and $\mathbf{2 4}^{+}$(Figure 8). That these intermediates are kinetically important was indirectly revealed by RRKM analysis that considered only the steps $\mathbf{1}^{+} \leftrightarrow \mathbf{1 0}^{+} \rightarrow \mathbf{2 2}^{+}+\mathrm{NH}_{3}$, where the first reversible step has a regular transition-state, and the second step was treated by variational TS theory at several points along the C-6. . $\mathrm{NH}_{3}$ coordinate. Under these conditions, the calculated molar fractions of $\mathbf{2 2}^{+}$ indicate that $10 \%$ dissociation would be achieved in $\mathbf{1}^{+}$ having $470-500 \mathrm{~kJ} \mathrm{~mol}^{-1}$ internal energies for dissoci-

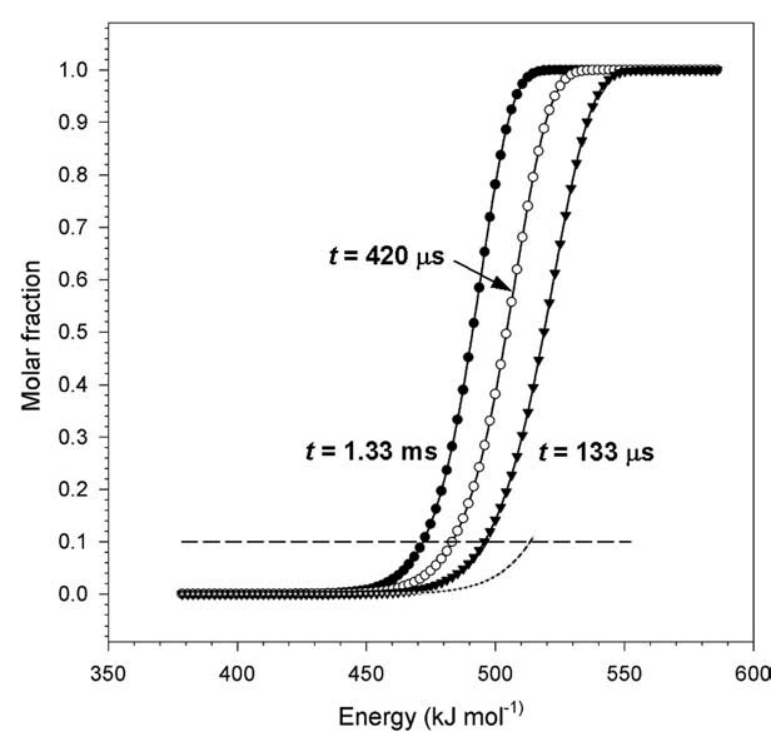

Figure 9. Energy and time-dependent molar fractions of $\mathbf{2 2}^{+}+$ $\mathrm{NH}_{3}$ from kinetic analysis of RRKM rate constants for $\mathbf{1}^{+} \leftrightarrow \mathbf{1 0}^{+} \rightarrow$ $22^{+}+\mathrm{NH}_{3}$. The dashed horizontal line indicates $10 \%$ dissociation corresponding to the CAD spectrum. The dashed curve is from $k(E)$ for the $\mathbf{1 0}^{+} \rightarrow \mathbf{2 2}^{+}+\mathrm{NH}_{3}$ step that was scaled by 0.1 .

ation times between $1.3 \mathrm{~ms}$ and $133 \mu \mathrm{s}$ (Figure 9). Clearly, this is incompatible with the rates for N-1/N-10 isomerization which will achieve only $8-12 \%$ equilibration within the same energy interval and at the same times. A tentative agreement with the experimental data can be achieved only if the dissociation rate to $22^{+}$ $+\mathrm{NH}_{3}$ had a shallower increase with the ion internal energy, as indicated by the shifted dotted curve for dissociation at $1.3 \mathrm{~ms}$ in Figure 9. Shallow $k(E)$ curves have been reported previously for dissociations involving very loose or barrierless transition states, where the rate constants predicted by RRKM are often greater than the experimental values $[18,19]$. The existence of ion-molecule complexes at the late stages of dissociation can further decrease the number of quantum states available at the dividing surface from which the dissociation proceeds to products, and thus decrease the reaction rate. A rigorous treatment of this problem would be a daunting task due to the size and complexity of the adenine system.

In view of the energetically possible mechanistic pathways for elimination of ammonia, the specific loss of $\mathrm{N}-1$ upon single-collision conditions [5] remains difficult to explain. The only intermediate of those we identified that is capable to eliminate N-1-containing ammonia without intervention of $\mathrm{N}-10$ is ion $18^{+}$ (Scheme 6). However, competing dissociations of $\mathbf{1 8}^{+}$ should favor complex $\mathbf{1 9}^{+}$and result in the formation of $\mathrm{NH}_{4}^{+}$as the energetically more favorable charged fragment. A tentative explanation of the single-collision CAD data would take into account dynamic effects in highly excited $\mathbf{1}^{+}$that irreversibly steer the dissociation into the channel $\mathbf{1}^{+} \rightarrow \mathbf{1 7}^{+} \rightarrow \mathbf{1 6}^{+} \rightarrow \mathbf{1 8}^{+} \rightarrow \mathbf{2 0}^{+}+\mathrm{NH}_{3}$. Another possibility is that the extremely small fraction 
of protonated adenine that was found to dissociate under single-collision conditions [5] sampled some high-energy adenine tautomers in which $\mathrm{N}-1$ was prone to be lost as ammonia.

\section{Conclusions}

Investigation of the structures and energies for a number of ions relevant to adenine protonation leads to the following conclusions. Protonation of adenine by electrospray most likely forms the N-1-protonated tautomer $\mathbf{1}^{+}$. This is the thermodynamically most stable structure in bulk water, gas-phase clusters with one or two water molecules, and as an isolated gas-phase species. Isomerizations to adenine tautomers protonated at N-3, N-7, and N-10 are all endoergic in bulk water, water clusters, and the gas phase, and these isomers are calculated to amount to $<3 \%$ at room temperature. From this we conclude that electrospray of adenine from aqueous solutions produces ions $\mathbf{1}^{+}$of high purity.

An energetically plausible mechanistic pathway was found for an isomerization of $\mathbf{1}^{+}$that results in switching $\mathrm{N}-1$ and $\mathrm{N}-10$ before loss of ammonia. This pathway involves a ring opening by cleavage of the $\mathrm{N}-1-\mathrm{C}-2$ bond, rotations and imine group flips in several intermediates, and a rate-determining proton migration from $\mathrm{N}-10$ to $\mathrm{N}-1$ in a ring-reformed intermediate. Kinetic analysis of the isomerizations and dissociations revealed kinetic shifts of more than $120 \mathrm{~kJ} \mathrm{~mol}^{-1}$ in both processes. In particular, very large kinetic shifts in the elimination of ammonia are necessary to make the $\mathrm{N}-1 / \mathrm{N}-10$ swapping competitive on the time scale compatible to those considered for collision-induced dissociations.

\section{Acknowledgments}

The authors gratefully acknowledge generous support of this work by the National Science Foundation (grants CHE-0349595 and CHE-0342956).

\section{References}

1. (a) Christensen, J. J.; Rytting, J. H.; Izatt, R. M. Thermodynamic $\mathrm{pK}, \Delta H^{\circ}, \Delta S^{\circ}$, and $\Delta C_{\mathrm{p}}{ }^{\circ}$ Values for Proton Dissociation from Several Purines and Their Nucleosides in Aqueous Solution. Biochemistry 1970, 9, 4907-4913. (b) Zimmer, S.; Biltonen, R. Thermodynamics of Proton Dissociation of Adenine. J. Solution Chem. 1972, 1, 291-298.

2. Major, D. T.; Laxer, A.; Fischer, B. Protonation Studies of Modified Adenine and Adenine Nucleotides by Theoretical Calculations and ${ }^{15}$ N NMR. J. Org. Chem. 2002, 67, 790-802.

3. Chen, X.; Syrstad, E. A.; Nguyen, M. T.; Gerbaux, P.; Tureček, F. Distonic Isomers and Tautomers of the Adenine Cation Radical in the Gas Phase and Aqueous Solution. J. Phys. Chem. A 2004, 108, 9283-9293.

4. Alexander, A. A.; Kebarle, P.; Fuciarelli, A. F.; Raleigh, J. A. Characterization of Radiation-Induced Damage to Polyadenylic Acid Using High-Performance Liquid Chromatography/ Tandem Mass Spectrometry. Anal. Chem. 1987, 59, 2484-2491.

5. Nelson, C. C.; McCloskey, J. A. Collision-Induced Dissociation of Adenine. J. Am. Chem. Soc. 1992, 114, 3661-3668.
6. Frisch, M. J.; Trucks, G. W.; Schlegel, H. B.; Scuseria, G. E.; Robb, M. A.; Cheeseman, J. R.; Montgomery, J. A., Jr.; Vreven, T.; Kudin, K. N.; Burant, J. C.; Millam, J. M.; Iyengar, S. S.; Tomasi, J.; Barone, V.; Mennucci, B.; Cossi, M.; Scalmani, G.; Rega, N.; Petersson, G. A.; Nakatsuji, H.; Hada, M.; Ehara, M.; Toyota, K.; Fukuda, R.; Hasegawa, J.; Ishida, M.; Nakajima, T.; Honda, Y.; Kitao, O.; Nakai, H.; Klene, M.; Li, X.; Knox, J. E.; Hratchian, H. P.; Cross, J. B.; Adamo, C.; Jaramillo, J.; Gomperts, R.; Stratmann, R. E.; Yazyev, O.; Austin, A. J.; Cammi, R.; Pomelli, C.; Ochterski, J., W.; Ayala, P. Y.; Morokuma, K.; Voth, G. A.; Salvador, P.; Dannenberg, J. J.; Zakrzewski, V. G.; Dapprich, S.; Daniels, A. D.; Strain, M. C.; Farkas, O.; Malick, D. K.; Rabuck, A. D.; Raghavachari, K.; Foresman, J. B.; Ortiz, J. V.; Cui, Q.; Baboul, A. G.; Clifford, S.; Cioslowski, J.; Stefanov, B. B.; Liu, G.; Liashenko, A.; Piskorz, P.; Komaromi, I.; Martin, R. L.; Fox, D. J.; Keith, T.; Al-Laham, M. A.; Peng, C. Y.; Nanayakkara, A.; Challacombe, M.; Gill, P. M. W.; Johnson, B.; Chen, W.; Wong, M. W.; Gonzalez, C.; Pople, J. A. Gaussian 03, Rev. B 05; Gaussian, Inc.: Pittsburgh, PA, 2003.

7. (a) Becke, A. D. A New Mixing of Hartree-Fock and LocalDensity-Funcional Theories. J. Chem. Phys. 1993, 98, 1372-1377. (b) Becke, A. D. Density Functional Thermochemistry. III. The Role of Exact Exchange. J. Chem. Phys. 1993, 98, 5648-5652. (c) Stephens, P. J.; Devlin, F. J.; Chabalowski, C. F.; Frisch, M. J. $\mathrm{Ab}$ Initio Calculation of Vibrational Absorption and Circular Dichroism Spectra Using Density Functional Force Fields. J. Phys. Chem. 1994, 98, 11623-11627.

8. Møller, C.; Plesset, M. S. Note on an Approximation Treatment for Many Electron Systems. Phys. Rev. 1934, 46, 618-622.

9. Tureček, F. Proton Affinity of Dimethyl Sulfoxide and Relative Stabilities of $\mathrm{C}_{2} \mathrm{H}_{6} \mathrm{OS}$ Molecules and $\mathrm{C}_{2} \mathrm{H}_{7} \mathrm{OS}^{+}$Ions. A Comparative G2(MP2) Ab Initio and Density Functional Theory Study. J. Phys. Chem. A 1998, 102, 4703-4713.

10. (a) Tureček, F.; Wolken, J. K. Dissociation Energies and Kinetics of Aminopyrimidinium Radicals by ab Initio and Density Functional Theory. J. Phys. Chem. A 1999, 103, 19051912. (b) Tureček, F.; Wolken, J. K.; Sadílek, M. Distinction of Isomeric Pyridyl Cations and Radicals by NeutralizationReionization Mass Spectrometry, ab Initio and Density Functional Theory Calculations. Eur. Mass Spectrom. 1998, 4, 321332. (c) Wolken, J. K.; Tureček, F. Heterocyclic Radicals in the Gas Phase. An Experimental and Computational Study of 3-Hydroxypyridinium Radicals and Cations. J. Am. Chem. Soc. 1999, 121, 6010-6018. (d) Wolken, J. K.; Tureček, F. Modeling Nucleobase Radicals in the Gas Phase. Experimental and Computational Study of 2-Hydroxypyridinium and 2(1H)Pyridone Radicals. J. Phys. Chem. A 1999, 103, 6268-6281. (e) Tureček, F.; Carpenter, F. H. Glycine Radicals in the Gas Phase. J. Chem. Soc. Perkin Trans. 2 1999, 2315-2323. (f) Polášek, M.; Tureček, F. Hydrogen Atom Adducts to Nitrobenzene: Formation of the Phenylnitronic Radical in the Gas Phase and Energetics of Wheland Intermediates. J. Am. Chem. Soc. 2000, 122, 9511-9524.

11. (a) Rablen, P. R. Is the Acetate Anion Stabilized by Resonance or Electrostatics? A Systematic Structural Comparison. J. Am. Chem. Soc. 2000, 122, 357-368. (b) Rablen, P. R.; Bentrup, K. H. Are the Enolates of Amides and Esters Stabilized by Electrostatics? J. Am. Chem. Soc. 2003, 125, 2142-2147.

12. Čižek, H.; Paldus, J.; Šroubková, L. Cluster Expansion Analysis for Delocalized Systems. Int. J. Quantum. Chem. 1969, 3, 149-167.

13. Purvis, G. D.; Bartlett, R. J. A Full Coupled-Cluster Singles and Doubles Model. The Inclusion of Disconnected Triples. J. Chem. Phys. 1982, 76, 1910-1918.

14. (a) Tomasi, J.; Cammi, R.; Mennucci, B.; Cappelli, C.; Corni, S. Molecular Properties in Solution Described with a Continuum Solvation Model. Phys. Chem. Chem. Phys. 2002, 4, 5697-5712. 
(b) Cossi, M.; Scalmani, G.; Rega, N.; Barone, V. New Developments in the Polarizable Continuum Model for Quantum Mechanical and Classical Calculations on Molecules in Solution. J. Chem. Phys. 2002, 117, 43-54.

15. Barone, V.; Cossi, M.; Tomasi, J. A New Definition of Cavities for the Computation of Solvation Free Energies by the Polarizable Continuum Model. J. Chem. Phys. 1997, 107, 3210-3221.

16. Zhu, L. Hase, W. L. Quantum Chemistry Program Exchange; Indiana University: Bloomington, IN 1994; Program No. QCPE 644.

17. Frank, A. J.; Sadílek, M.; Ferrier, J. G.; Tureček, F. Sulfur Oxyacids and Radicals in the Gas Phase. A Variable-Time NeutralizationPhotoexcitation-Reionization Mass Spectrometric and ab Initio/ RRKM Study. J. Am. Chem. Soc. 1997, 119, 12343-12353.

18. Hase, W. L.; Wardlaw, D. M. 1989; Transition-State Theory Rate Constants for Association Reactions Without Potential Energy Barriers. In Advances in Gas-Phase Photochemistry and Kinetics, Bimolecular Collisions; Ashfold, M. N. R.; Baggott, J. E., Eds.; Royal Society of Chemistry: London, Chap IV, pp 171-207.

19. Hase, W. L. Variational Unimolecular Rate Theory. Acc. Chem. Res. 1983, 16, 258-264

20. Seymour, J. L.; Syrstad, E. A.; Langley, C. C.; Tureček, F. Neutralization-Reionization of Ions Produced by Electrospray. Instrument Design and Initial Data. Int. J. Mass Spectrom. 2003, 228, 687-702.

21. (a) Podolyan, Y.; Gorb, L.; Leszczynski, J. Protonation of Nucleic Acid Bases. A Comprehensive Post-Hartree-Fock Study of the Energetics and Proton Affinities. J. Phys. Chem. A 2000, 104, 7346-7352. (b) Del Bene, J. E. Molecular Orbital Study of the Protonation of DNA Bases. J. Phys. Chem. 1983, 87, 367-371. (c) Mezey, P. G. Nonempirical SCF MO Studies on the Protonation of Biopolymer Constituents. II. Protonation of Adenine, Guanine, and Their Tautomeric Forms. Theor. Chim. Acta 1980, 54, 251-258. (d) Bonaccorsi, R.; Pullman, A.; Scrocco, E.; Tomasi, J. Molecular Electrostatic Potentials for the Nucleic Acid Bases. Adenine, Thymine, and Cytosine. Theor. Chim. Acta 1972, 24, 51-60.
22. (a) Bohme, D. K.; Mackay, G. I.; Schiff, H. I. Determination of Proton Affinities from the Kinetics of Proton Transfer Reactions. VII. The Proton Affinities of $\mathrm{O}_{2}, \mathrm{H}_{2}, \mathrm{Kr}, \mathrm{O}, \mathrm{N}_{2}, \mathrm{Xe}, \mathrm{CO}_{2}$, $\mathrm{CH}_{4}, \mathrm{~N}_{2} \mathrm{O}$, and CO. J. Chem. Phys. 1980, 73, 4976-4986. (b) Harrison, A. G. Chemical Ionization Mass Spectrometry, 2nd ed.; CRC Press: Boca Raton, 1992; p 18.

23. Szekely, G.; Allison, J. If the Ionization Mechanism in FastAtom Bombardment Involves Ion/Molecule Reactions, What are the Reagent Ions? The Time Dependence of Fast-Atom Bombardment Mass Spectra and Parallels to Chemical Ionization. J. Am. Soc. Mass Spectrom. 1997, 8, 337-351.

24. Eigen, M. Proton Transfer, Acid-Base Catalysis, and Enzymic Hydrolysis. I. Elementary Processes. Angew. Chem. 1963, 75, 489-508.

25. Kebarle, P.; Tang, L. From Ions in Solution to Ions in the Gas Phase-the Mechanism of Electrospray Mass Spectrometry. Anal. Chem. 1993, 65, 972A-986A.

26. Gatlin, C. L.; Tureček, F. Acidity Determination in Droplets Formed by Electrospraying Methanol-Water Solutions. Anal. Chem. 1994, 66, 712-718.

27. Hanus, M.; Kabeláč, M.; Rejnek, J.; Ryjáček, F.; Hobza, P. Correlated ab Initio Study of Nucleic Acid Bases and Their Tautomers in the Gas Phase, in a Microhydrated Environment, and in Aqueous Solution. Part 3. Adenine. J. Phys. Chem. B 2004, 108, 2087-2097.

28. Reed, A. E.; Weinstock, R. B.; Weinhold, F. Natural Population Analysis. J. Chem. Phys. 1985, 83, 735-746.

29. Connors, K. A. Chemical Kinetics; VCH Publishers: New York, 1990; pp 93-96.

30. Lifshitz, C. Time-Resolved Appearance Energies, Breakdown Graphs, and Mass Spectra; the Elusive Kinetic Shift. Mass Spectrom. Rev. 1982, 1, 309-348.

31. Chesnavich, W. J.; Bass, L.; Su, T.; Bowers, M. T. Multiple Transition States in Unimolecular Reactions: A Transition State Switching Model. Application to the $\mathrm{C}_{4} \mathrm{H}_{8}^{+\cdot}$ System. J. Chem. Phys. 1981, 74, 2228-2246. 